\title{
Intercomparison of aerosol-cloud-precipitation interactions in stratiform orographic mixed-phase clouds
}

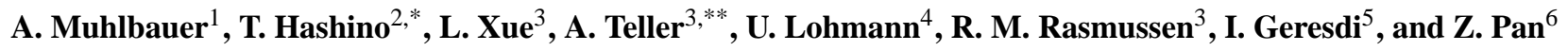 \\ ${ }^{1}$ Joint Institute for the Study of the Atmosphere and Ocean/Department of Atmospheric Sciences, University of Washington, \\ Seattle, Washington, USA \\ ${ }^{2}$ University of Wisconsin, Madison, Wisconsin, USA \\ ${ }^{3}$ Research Applications Laboratory, National Center for Atmospheric Research, Boulder, Colorado, USA \\ ${ }^{4}$ Institute for Atmospheric and Climate Science, ETH Zurich, Zurich, Switzerland \\ ${ }^{5}$ Institute of Environmental Sciences, University of Pecs, Hungary \\ ${ }^{6}$ Department of Earth and Atmospheric Sciences, Saint Louis University, Saint Louis, Missouri, USA \\ *now at: Atmosphere and Ocean Research Institute, The University of Tokyo, Chiba, Japan \\ ** now at: The Cyprus Institute, Nicosia, Cyprus
}

Received: 22 February 2010 - Published in Atmos. Chem. Phys. Discuss.: 21 April 2010

Revised: 20 July 2010 - Accepted: 30 August 2010 - Published: 2 September 2010

\begin{abstract}
Anthropogenic aerosols serve as a source of both cloud condensation nuclei (CCN) and ice nuclei (IN) and affect microphysical properties of clouds. Increasing aerosol number concentrations is hypothesized to retard the cloud droplet coalescence and the riming in mixed-phase clouds, thereby decreasing orographic precipitation.

This study presents results from a model intercomparison of 2-D simulations of aerosol-cloud-precipitation interactions in stratiform orographic mixed-phase clouds. The sensitivity of orographic precipitation to changes in the aerosol number concentrations is analysed and compared for various dynamical and thermodynamical situations. Furthermore, the sensitivities of microphysical processes such as coalescence, aggregation, riming and diffusional growth to changes in the aerosol number concentrations are evaluated and compared.

The participating numerical models are the model from the Consortium for Small-Scale Modeling (COSMO) with bulk microphysics, the Weather Research and Forecasting (WRF) model with bin microphysics and the University of Wisconsin modeling system (UWNMS) with a spectral ice habit prediction microphysics scheme. All models are operated on a cloud-resolving scale with $2 \mathrm{~km}$ horizontal grid spacing.

The results of the model intercomparison suggest that the sensitivity of orographic precipitation to aerosol modifica-
\end{abstract}

tions varies greatly from case to case and from model to model. Neither a precipitation decrease nor a precipitation increase is found robustly in all simulations. Qualitative robust results can only be found for a subset of the simulations but even then quantitative agreement is scarce. Estimates of the aerosol effect on orographic precipitation are found to range from $-19 \%$ to $0 \%$ depending on the simulated case and the model.

Similarly, riming is shown to decrease in some cases and models whereas it increases in others, which implies that a decrease in riming with increasing aerosol load is not a robust result. Furthermore, it is found that neither a decrease in cloud droplet coalescence nor a decrease in riming necessarily implies a decrease in precipitation due to compensation effects by other microphysical pathways.

The simulations suggest that mixed-phase conditions play an important role in buffering the effect of aerosol perturbations on cloud microphysics and reducing the overall susceptibility of clouds and precipitation to changes in the aerosol number concentrations. As a consequence the aerosol effect on precipitation is suggested to be less pronounced or even inverted in regions with high terrain (e.g., the Alps or Rocky Mountains) or in regions where mixed-phase microphysics is important for the climatology of orographic precipitation. 


\section{Introduction}

Orographic clouds form as moist air impinges on mountain ranges thereby potentially forming orographic precipitation which is essential for landscape formation, agriculture and the hydrology of watersheds in many regions of the world (e.g., Roe, 2005). Understanding the various dynamical processes leading to orographic precipitation have been objectives of several field experiments such as the Mesoscale Alpine Programme (MAP, Bougeault et al. 2001) and the Improvement of Microphysical Parameterization Through Observational Verification Experiment (IMPROVE-2, Stoelinga et al. 2003). However, the complexity of mixed-phase microphysical processes acting in orographic clouds and the sensitivity of orographic precipitation to changes in microphysics are not fully understood yet (e.g., Rotunno and Houze, 2007) and remain challenging to represent in numerical models of weather and climate on various scales.

An open question regarding microphysical effects on orographic clouds is weather aerosol particles can significantly influence the amount and distribution of precipitation from these clouds. Orographic precipitation is hypothesized to be susceptible to aerosols because the time available to form precipitable hydrometeors in rising air parcels is constrained by the flow over the mountain. Increasing the aerosol number concentration is observed to lead to a shift of the cloud droplet spectrum towards smaller sizes (e.g., Twomey et al., 1984; Lowenthal et al., 2004) and, thus, retards the onset of the coalescence process. Microphysical observations in mixed-phase clouds also suggest a decrease in the snowfall rate with increasing aerosol number concentration due to a reduced efficacy of the riming process implied by smaller cloud droplets (Borys et al., 2000, 2003). Both effects together may modulate the amount and distribution of mixedphase precipitation over mountainous terrain.

However, several in-situ and airborne observations in orographic clouds show that, besides their ability to act as cloud condensation nuclei ( $\mathrm{CCN})$, aerosols are important for the initiation of ice in orographic clouds by heterogeneous ice nucleation (Field et al., 2001; Targino et al., 2006; Mertes et al., 2007; Cozic et al., 2008). Measurements from the Cloud and Aerosol Characterization Experiment (CLACE, Choularton et al., 2008) indicate the potential of aerosols to influence the partitioning between the liquid and the ice phase in mixed-phase orographic clouds thereby controlling the microphysical growth regime of hydrometeors (Verheggen et al., 2007). The ability of aerosols to serve as ice nuclei (IN) in various heterogeneous nucleation modes (see Vali 1985) depends on environmental factors such as temperature and ice supersaturation but also on a variety of aerosol properties like lattice structure, surface defects, chemical composition, etc. (Pruppacher and Klett, 1997; Baker and Peter, 2008; Hegg and Baker, 2009; Kulkarni and Dobbie, 2010). Based on the results of laboratory experi- ments, mineral dust and black carbon aerosols are deemed to be good ice nuclei (Roberts and Hallett, 1968; Gorbunov et al., 2001). Ice residual measurements during several field campaigns corroborate the ability of dust (e.g., DeMott et al., 2004; Cziczo et al., 2004) and black carbon aerosols (e.g., Mertes et al., 2007; Cozic et al., 2008) to act as IN which for the latter one also suggests an anthropogenic impact of aerosols on clouds. However, laboratory studies also indicate that the mixing/processing state of aerosols can significantly alter the IN abilities which still is a matter of considerable debate. So far, it is found that coating of particles with sulphuric acid or organics increases the onset supersaturation for heterogeneous nucleation in the deposition mode and lowers the freezing temperatures in the immersion mode. This renders coated, processed or aged substrates of black carbon or mineral dust less efficient for heterogeneous nucleation when compared with the uncoated samples (e.g., Mohler et al., 2005; Kanji and Abbatt, 2006; Mohler et al., 2008).

Statistical quantifications of aerosols affecting orographic precipitation based on paired rain gauge data are so far controversial and partially contradicting (e.g., Givati and Rosenfeld 2004, Jirak and Cotton 2006, Alpert et al. 2008, amongst others). A particular difficulty arising in these studies is to separate the aerosol effect on precipitation from urban/heat island effects or other climatological changes (e.g., changes in circulation patterns, synoptic changes) and it is argued that inferences from these methods can be misleading (Paldor, 2008; Mühlbauer, 2009). As a consequence, estimates of the effects of aerosols on orographic precipitation from observations remain inconclusive and uncertain (e.g., Denman et al., 2007; Levin and Cotton, 2009; Khain, 2009) which in turn justifies the use of numerical models.

Early numerical simulations by Hobbs et al. (1973) show that the microphysical growth regime by which hydrometeors develop in orographic clouds influences the orographic precipitation distribution. Simulations of winter-time orographic clouds suggest that the amount of orographic precipitation is sensitive to the available $\mathrm{CCN}$ and show decreasing precipitation for increasing $\mathrm{CCN}$ (Chaumerliac et al., 1987; Thompson et al., 2004). Similarly, Lynn et al. (2007) find a decrease of orographic precipitation if the background aerosol conditions change from maritime to continental. However, Lynn et al. (2007) also report a sensitivity of the aerosol effect on orographic precipitation with respect to relative humidity. In a work on the classification of aerosol effects on precipitation Khain et al. (2008) conclude that orographic precipitation is decreased with increasing aerosol number if the environmental conditions at which orographic clouds form are relatively dry. Muhlbauer and Lohmann (2008) find decreasing orographic precipitation with increasing aerosol number concentrations for warmphase orographic clouds at relative humidities of $80 \%$ but the sensitivities crucially depend on the geometry of the mountain and the dynamical flow regime. In the case of orographic 
flow blocking the effect of aerosols in decreasing orographic precipitation is greatly reduced or even inverted.

Nevertheless, it is not clear how aerosols can influence precipitation in mixed-phase orographic clouds where the efficient formation of precipitable hydrometeors does not hinge on the coalescence process alone. Indeed, Saleeby and Cotton (2009) conduct simulations of winter-time orographic seeder-feeder clouds and found that precipitation tends to be redistributed rather than suppressed even if the riming efficiencies in these clouds are decreased. In addition, simulations of mixed-phase orographic clouds by Muhlbauer and Lohmann (2009) suggest that the heterogeneous freezing ability of aerosols (i.e., the heterogeneous freezing mode) can control the sign and the magnitude of the aerosol effect on orographic precipitation. These results highlight the importance of the ice phase for aerosol-cloud-precipitation interaction problems.

However, microphysical sensitivity studies in the past also show large impacts and variability of the results depending on the numerical approach followed in the models to treat microphysical processes (e.g., Morrison and Grabowski, 2007; Li et al., 2009). For example, bulk microphysical parametrisations typically rely on some assumed form of hydrometeor size distributions which introduces additional uncertainties. In contrast, bin resolving microphysical models explicitly calculate the particle size distributions without assumptions on the shape and slope parameter. Nevertheless, for computing microphysical collection processes (i.e., coalescence, aggregation and riming) both modeling approaches rely on assumptions for the collection efficiencies which are usually derived from laboratory experiments or numerical simulations (e.g., Khain et al., 2000).

Thus, the main goal of this paper is to analyse and intercompare the sensitivities of different microphysical processes in mixed-phase orographic clouds and orographic precipitation to changes in the ambient aerosol conditions using several state-of-the-art numerical models and microphysical approaches. Special emphasis is placed on the sensitivity of the riming process. Thus, we address the following science questions:

- Is it possible to get qualitative robust estimates of the sensitivity of orographic precipitation to changing aerosol conditions for dynamically idealized conditions?

- Do increases in the aerosol number concentration affect the cloud droplet coalescence and the riming process in mixed-phase orographic clouds?

- Do reductions in coalescence and riming from increases in aerosol number concentrations imply a reduction of precipitation from mixed-phase orographic clouds or are there compensating effects such as enhanced aggregation?
In order to reduce the complexity of the problem, the simulations are performed within an idealized setup of a 2-D flow over a mountain introduced at the Seventh WMO International Cloud Modeling Workshop (Morrison et al., 2009).

The paper is structured as follows: the participating models and microphysical parametrisations are introduced in Sect. 2. The design and the setup of the model intercomparison is outlined in Sect. 3. In Sect. 4 the results of the different modeling approaches are presented. A discussion of the key findings and conclusions are presented in Sect. 5.

\section{Model descriptions}

The model intercomparison is comprised of three participating models namely the Consortium for Small-Scale Modeling's (COSMO) model with coupled bulk double moment aerosol-cloud microphysics, the Weather Research and Forecasting (WRF) model with bin microphysics and the University of Wisconsin modeling system (UWNMS) with SHIPS microphysics. Details of the microphysical parametrisations of each model are given in Table 1.

\subsection{COSMO}

The COSMO model is a non-hydrostatic, fully compressible limited-area mesoscale weather prediction model (http: //www.cosmo-model.org, Doms and Schättler, 2002; Steppeler et al., 2003). The elastic equations are solved in a split-explicit time-splitting approach (Wicker and Skamarock, 2002) with a two time-level total variation diminishing (TVD) third order Runge-Kutta scheme in combination with a fifth order horizontal advection scheme. All moisture variables and aerosols are advected by a fourth order positive definite advection scheme after Bott (1989). A Smooth Level Vertical (SLEVE) coordinate system (Schär et al., 2002) is used in the vertical and a Rayleigh damping layer is introduced in the upper parts of the computational domain to minimize reflections of vertically propagating gravity waves from the rigid upper model boundary.

Coupled aerosol and cloud-microphysical processes are parametrised in a double moment approach for five hydrometeor species (i.e., cloud droplets, rain, ice crystals, snow, graupel) and aerosols with various chemical compositions (i.e., sulphate, black carbon, organic carbon, sea salt, dust). The warm-phase microphysical processes of the scheme include the nucleation of cloud droplets, condensation/evaporation of cloud droplets, autoconversion of cloud droplets to rain (i.e., the collision of cloud droplets leading to rain drops), accretion of cloud droplets by rain (i.e., the collection of cloud droplets by rain drops), self-collection of cloud-droplets and rain, evaporation of rain and the breakup of large rain drops. In the present version of the model the aerosol activation is treated by following the $\kappa$-Köhler theory of Petters and Kreidenweis (2007). The ice-phase 
Table 1. Details of the microphysical parametrisations used in the models.

\begin{tabular}{llll}
\hline & COSMO & WRF & UWNMS \\
\hline Collision efficiencies & Pinsky et al. (2001) & Hall (1980) & Pinsky et al. (2001) \\
Aggregation efficiencies & Seifert and Beheng (2006) & Pitter (1977) & Hallgren and Hosler (1960) \\
Riming efficiencies & Lew et al. (1986), Mitchell (1990) & Lin et al. (1983) & Hashino and Tripoli (2007) \\
Terminal fall speeds ice & Heymsfield and Kajikawa (1987) & Hobbs (1974) & Bohm (1992) \\
Terminal fall speeds snow & Locatelli and Hobbs (1974) & Passarelli and Srivastava (1979) & Bohm (1992) \\
Terminal fall speeds graupel & Locatelli and Hobbs (1974) & Rasmussen and Heymsfield (1987) & Bohm (1992) \\
\hline
\end{tabular}

processes include heterogeneous nucleation, secondary ice nucleation, freezing, melting, vapour deposition, sublimation, riming, aggregation, collection and conversion to graupel (see Table 1 for details). For details of the microphysics parametrisation we refer the interested reader to Seifert and Beheng (2006); Muhlbauer and Lohmann (2008) and references therein.

\subsection{WRF}

The Advanced Research WRF model version three (Klemp et al., 2007; Skamarock and Klemp, 2008) is used with terrain-following vertical coordinates and a new gravity wave absorbing layer according to Klemp et al. (2008). For the advection of scalar quantities the positive definite and shape preserving advection scheme of Wang et al. (2009) is employed. A detailed bin microphysics scheme is implemented in WRF and described in Geresdi (1998), Rasmussen et al. (2002) and Geresdi and Rasmussen (2005). The bin schemes use the multi moment conservation method (Tzivion et al., 1987; Reisin et al., 1996) to insure the conservation of mass and number concentrations over 36 bins. Evolution equations are solved explicitly for the size distributions of cloud droplets, rain, ice crystals, snow and graupel (see Table 1 for details). The warm-phase microphysical processes include the activation of aerosols to cloud droplets, diffusional growth of drops (i.e., condensation/evaporation), coalescence of drops (i.e., autoconversion, accretion, and selfcollection) and break-up of drops. Contrary to Rasmussen et al. (2002), aerosol activation and cloud droplet nucleation is treated here by calculating the supersaturation and critical diameter according to Köhler theory (Pruppacher and Klett, 1997; Xue et al., 2010). Hence, 40 more bins are added to the microphysics scheme to resolve the aerosol size distribution in the range $0.013-105 \mu \mathrm{m}$. The diffusional growth of the wetted aerosols is treated by the method described in Kogan (1991) and Teller and Levin (2006).

Ice-phase microphysical processes include diffusional growth of ice crystals, snow and graupel (i.e., deposition/sublimation), aggregation, riming and melting. Heterogeneous nucleation of ice crystals is considered through freezing of supercooled droplets (immersion freezing, contact freezing) and due to deposition and condensation nucle- ation. Secondary ice formation includes the Hallett-Mossop ice multiplication process.

\subsection{UWNMS}

The University of Wisconsin non-hydrostatic modeling system (UWNMS) is a regional mesoscale model that is designed for high resolution cloud resolving simulations employing a variable stepped topography (VST) coordinate system (Tripoli, 1992; Tripoli and Smith, 2010). The dynamical core of UWNMS is formulated to conserve vorticity, kinetic energy, and enstrophy with a quasi-compressible closure. A numerical filter is employed to control nonlinear instabilities and spurious numerical noise. For the advection of scalar variables a positive definite nonlinear piecewise parabolic method is used.

Cloud-microphysical processes are predicted with the Advanced Microphysics Prediction System (AMPS, Hashino and Tripoli, 2007, 2008, 2010a,b) which simulates the detailed spectra of liquid, ice and aerosol particles. The liquid parametrisation is called SLiPS (Spectral Liquid Prediction System) which is a double moment mass bin model. The size spectrum ranges from $0.1 \mu \mathrm{m}$ to $0.5 \mathrm{~mm}$ radius with $30 \mathrm{bins}$ employed. The ice phase is parametrised in SHIPS which simulates 14 particle property variables over 20 double moment mass bins. The main aim of SHIPS is to keep track of the growth history of ice particles and evolve the particles properties explicitly in the Eulerian dynamics model. Given the particle property variables, the average habit and type of ice particles is diagnosed for each mass bin. Hence, no categorization of ice particles is necessary. The aerosols are handled by SAPS (Spectral Aerosol Prediction System) which simulates two moments of three lognormal distributions to describe Aitken, accumulation, and coarse modes of CCN and one monodisperse distribution of IN.

The current version of SHIPS includes heterogeneous nucleation, condensation/evaporation, deposition/sublimation, coalescence, aggregation, riming, freezing, melting as well as the break-up of rain drops and large snow flakes (see Table 1 for details). The activation of aerosols is treated according to Köhler theory. 
Table 2. Parameter specifications for the idealized set of simulations. All simulations are conducted with a sea-level pressure of $p_{\mathrm{sl}}=1000 \mathrm{hPa}$, a dry Brunt-Väisälä frequency of $N_{d}=0.011 \mathrm{~s}^{-1}$ and a mountain half-width of $a_{0}=20 \mathrm{~km}$. Aerosol conditions are prescribed according to a clean case (CC) or a polluted case (PC).

\begin{tabular}{lccc}
\hline Simulation & $\mathrm{h}(\mathrm{m})$ & $T_{\mathrm{SL}}(\mathrm{K})$ & aerosol \\
\hline SIM_1_CC & 800 & 280 & $\mathrm{CC}$ \\
SIM_1_PC & 800 & 280 & PC \\
SIM_2_CC & 800 & 273 & $\mathrm{CC}$ \\
SIM_2_PC & 800 & 273 & PC \\
SIM_3_CC & 3000 & 280 & CC \\
SIM_3_PC & 3000 & 280 & PC \\
SIM_4_CC & 3000 & 273 & CC \\
SIM_4_PC & 3000 & 273 & PC \\
\hline
\end{tabular}

\section{Design of the model intercomparison}

\subsection{Model setup}

All models use a 2-D computational domain with 401 grid points in the horizontal and 60 prescribed vertical levels. The model grid spacing is $2 \mathrm{~km}$. In order to make the models dynamically as comparable as possible, radiation, turbulence and convection parametrisations are switched off. Furthermore, a free-slip condition is imposed at the lower model boundary. In all models, heterogeneous ice nucleation is treated by following the Meyers et al. (1992) formulation for deposition/condensation nucleation. The diffusional growth on existing hydrometeors is calculated explicitly by solving the diffusional growth equation (Pruppacher and Klett, 1997).

\subsection{Initial conditions}

All experiments consider the development of an isolated orographic cloud and orographic precipitation for a 2-D mountain flow ${ }^{1}$. A series of sensitivity experiments are conducted by changing aerosol initial conditions, temperature profiles and mountain heights as summarized in Table 2.

The initial vertical profiles of temperature and dew-point temperature are shown in Fig. 1 and are given analytically by prescribing a sea-level temperature $T_{\mathrm{SL}}$, sea-level pressure $p_{\text {SL }}$ and dry Brunt-Väisälä frequency $N_{d}$ following Clark and Farley (1984).

The sea-level temperature is varied between $T_{\mathrm{SL}}=273 \mathrm{~K}$ and $T_{\mathrm{SL}}=280 \mathrm{~K}$ to generate two different thermodynamical conditions. The vertical profile of the relative humidity is given by

$\mathrm{RH}(z)=a+\frac{b-a}{1+\exp \left[-c\left(z-z_{0}\right)\right]}$,

\footnotetext{
${ }^{1} \mathrm{~A}$ fortran code to generate the initial conditions is available at http://www.rap.ucar.edu/ $\sim$ gthompsn/workshop2008/ or from the first author.
}

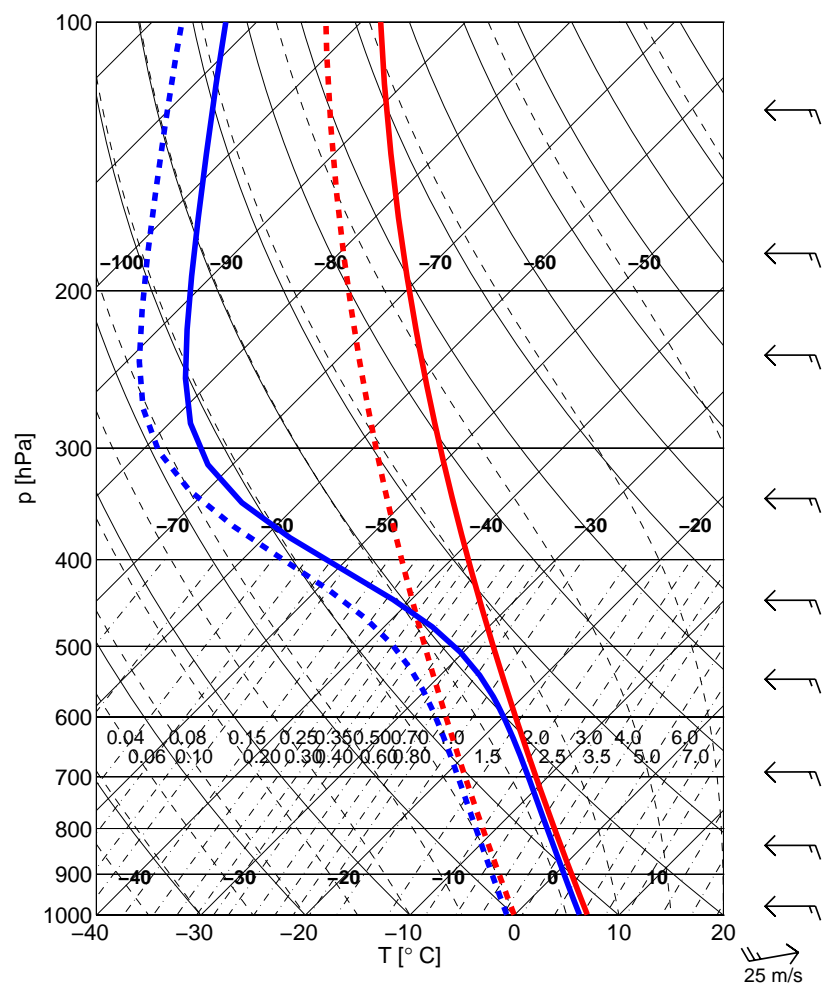

Fig. 1. Atmospheric soundings for the idealized 2-D simulations showing the temperature (red) and the dew-point temperature (blue) in a skewT-logp diagram. The warm sounding (solid) is used in simulations SIM_1 and SIM_3 whereas the cold sounding (dashed) is used in simulations SIM_2 and SIM_4 (see Table 2 for details on the setup).

with the parameters $a=0.95, b=0.03, c=0.0015 \mathrm{~m}^{-1}$, $z_{0}=6000 \mathrm{~m}$ and $0 \leq \mathrm{RH} \leq 1$ and a sea-level relative humidity of $\mathrm{RH}_{\mathrm{SL}}=95 \%$. The wind speed is $U=15 \mathrm{~m} \mathrm{~s}^{-1}$. It is prescribed constant with height within the first $10 \mathrm{~km}$ and increases linearly above to $U=40 \mathrm{~m} \mathrm{~s}^{-1}$ at the model top.

The idealized bell-shaped topography has the form

$h(x)=\left\{\begin{array}{cc}\frac{h_{0}}{16}\left[1+\cos \left(\pi \frac{x-x_{0}}{4 a_{0}}\right)\right]^{4} & ,\left|x-x_{0}\right|<4 a_{0} \\ 0 & ,\left|x-x_{0}\right|>4 a_{0},\end{array}\right.$

with $h_{0}$ denoting the peak mountain height located at $x_{0}$ (the middle of the computational domain) and $a_{0}$ denotes the halfwidth of the mountain. In the first set of experiments (linear hydrostatic mountain wave, SIM_1 and SIM_2) the mountain height is $h_{0}=800 \mathrm{~m}$ and the mountain half-width is $a_{0}=20 \mathrm{~km}$. In the second set of experiments (blocked flow, SIM_3 and SIM_4) the mountain height is $h_{0}=3000 \mathrm{~m}$.

The physical aerosol properties used to initialize the models are taken from observations by Weingartner et al. (1999) and are prescribed vertically constant by means of lognormal aerosol size distributions shown in Fig. 2. 


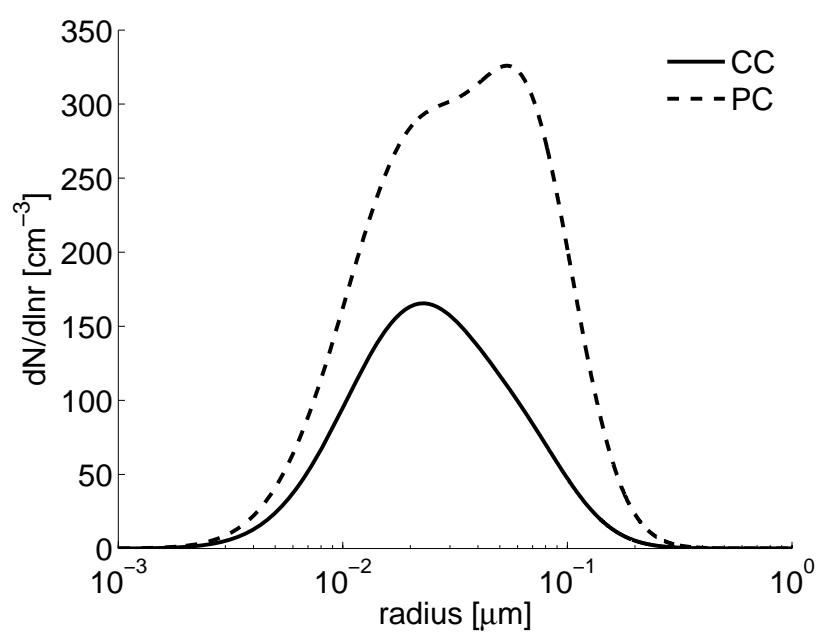

Fig. 2. Aerosol initial conditions for the idealized 2-D simulations. The number density distribution is based on a mean aerosol spectrum for winter and summer conditions, respectively. The winter aerosol spectrum is taken as the clean case (CC, solid) and the summer aerosol spectrum is taken as the polluted case (PC, dashed).

The aerosol spectra are representative for mean remote continental winter/summer conditions in the Alps. Since lower aerosol number densities are observed during winter than during summer the mean winter aerosol spectrum is taken as the clean case (CC) and the mean summer aerosol spectrum is taken as the polluted case (PC). Each aerosol spectrum satisfies a superposition of two lognormal size distributions of the form

$\frac{d N}{d \ln r}=\sum_{i=1}^{2} \frac{N_{i}}{\sqrt{2 \pi} \ln \sigma_{i}} \exp \left[-\left(\frac{\ln r-\ln \tilde{r}_{i}}{\sqrt{2} \ln \sigma_{i}}\right)^{2}\right]$

with the aerosol number densities $N_{i}$, the count median radii $\tilde{r}_{i}$ and the geometric standard deviations $\sigma_{i}$ specified according to Table 3.

Assuming a mean aerosol density of $\rho=1.5 \mathrm{~g} \mathrm{~cm}^{-3}$ yields aerosol mass densities of $2.0 \mathrm{\mu g} \mathrm{m}^{-3}$ during summer and $0.51 \mathrm{~g} \mathrm{~m}^{-3}$ during winter. In case models are able to discriminate different aerosol chemical compositions we adopt the results of aerosol mass spectrometry (see Fig. 11 in Cozic et al., 2008 for details) obtained during the CLACE field campaign at the Jungfraujoch in Switzerland. Otherwise, aerosols are assumed to consist of ammonium sulphate with $100 \%$ solubility.

\subsection{Intercomparison strategy}

In order to compare the sensitivities of microphysical processes in mixed-phase orographic clouds and orographic precipitation to changes in the aerosol initial conditions among the models the following metrics are used: the amount of precipitation from rain, snow and graupel as well as the orographic precipitation distribution are compared for all mod-
Table 3. Parameters of the lognormal aerosol size distributions.

\begin{tabular}{lccccc}
\hline & Mode & $N\left(\mathrm{~cm}^{-3}\right)$ & $\tilde{r}(\mu \mathrm{m})$ & $\sigma$ & $M\left(\mu \mathrm{g} \mathrm{m}^{-3}\right)$ \\
\hline Clean case & Ait. & 310 & 0.022 & 2.13 & 0.07 \\
& Acc. & 40 & 0.070 & 1.61 & 0.44 \\
Polluted case & Ait. & 530 & 0.022 & 2.13 & 0.26 \\
& Acc. & 260 & 0.070 & 1.61 & 1.74 \\
\hline
\end{tabular}

els after $10 \mathrm{~h}$ of simulation. Estimates for the total domain precipitation (TP), the spillover factor (SP) and the drying ratio (DR) are presented. Throughout this study, SP is defined as the leeward precipitation fraction (i.e. the ratio of leeward precipitation to total precipitation) according to Jiang and Smith (2003). DR is defined as the ratio of horizontally integrated total precipitation flux at the surface to the vertically integrated water vapour influx (e.g., Smith et al., 2003). SP and DR provide integral measures for orographic precipitation and do not depend on the choice of reference points at the topography. Both measures may be compared against observations from field campaigns, estimates from rain gauge networks and isotopic analyses of stream water or sap water on a climatological time scale (e.g., Smith et al., 2005). Cloud-microphysical fields (e.g., cloud droplet number concentration, liquid water content) are compared after $10 \mathrm{~h}$ of simulation. Averaged values of liquid water path (LWP) and ice water path (IWP) are compared among the models as a function of time. Statistics of the dynamics of the individual models are computed for the computational domain excluding relaxation and damping zones. Furthermore, microphysical conversion rates for coalescence, aggregation, riming and diffusional growth are analysed and compared to get a better insight into aerosol-cloud-precipitation interactions on a process based level.

\section{Results}

\subsection{Simulations of orographic precipitation without flow blocking}

For the first set of simulations a 2-D moist unblocked flow over a mountain is considered (i.e., a setup where linear theory predicts a hydrostatic mountain wave) for a warm case (SIM_1_CC, SIM_1_PC) and a cold case (SIM_2_CC, SIM_2_PC) (see Table 2 for details on the setup).

\subsubsection{Dynamics comparison}

In order to show that the models are simulating the same dynamical state, the statistics of the wind velocities and the specific humidity are compared in Fig. 3.

All models are able to simulate the hydrostatic mountain wave with an upstream region of flow deceleration and a downstream region of flow acceleration (not shown). All 

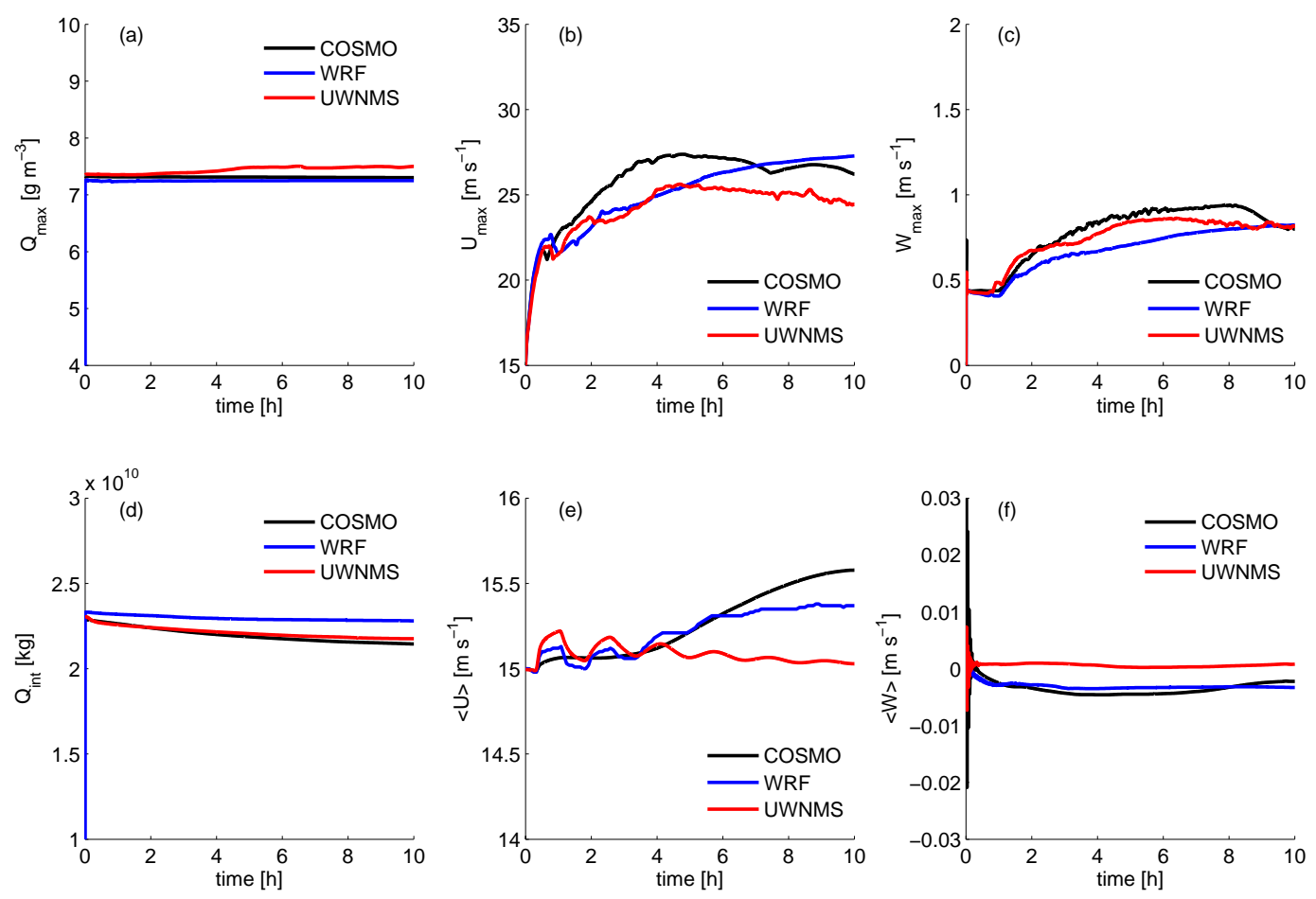

Fig. 3. Time evolution of water vapour, horizontal and vertical wind velocities for simulation SIM_1_CC. The upper panel shows maximum values of specific humidity $Q_{\max }(\mathbf{a})$, horizontal wind speeds $U_{\max }$ (b) and vertical wind speeds $W_{\max }$ (c). The lower panel shows domain integrated water vapour $Q_{\text {int }}(\mathbf{d})$, domain average horizontal wind speeds $\langle U>$ (e) and domain averaged vertical wind speeds $<W>$ (f). The individual models shown are COSMO (black), WRF (blue) and UWNMS (red).

simulations start with a maximum specific humidity of approximately $7.3 \mathrm{~g} \mathrm{~m}^{-3}$ at the lowest model level according to the sounding shown in Fig. 1. The maximum values of specific humidity stay fairly constant throughout the simulations for all models except for UWNMS which develops a slight increase in the maximum specific humidity. This increase in maximum specific humidity is caused by stronger evaporation processes on the upstream side of the mountain at the levels close to the surface.

The integrated water vapour decreases over time according to the individual model's precipitation amount. For example, the domain integrated water vapour stays highest in WRF throughout the whole simulation because WRF is the model with the lowest total precipitation rates as will be discussed later. Note that the slight differences in the domain integrated water vapour initially originate from differences in the model sampling volume. Since each model applies a different numerical setup (e.g., depth of the Rayleigh damping layer, width of the lateral relaxation zone) the model sampling volume varies slightly among the models. The maximum and domain integrated statistics are obtained for the entire model domain excluding relaxation and damping zones.

The horizontal wind speeds are prescribed at $15 \mathrm{~m} \mathrm{~s}^{-1}$ at the initial time and increase throughout the simulation to roughly $26 \mathrm{~m} \mathrm{~s}^{-1}$ in the downdraught region on the leeward side of the mountain after $10 \mathrm{~h}$ simulation time. The dif- ferences in maximum horizontal wind velocities among the models are within a range of $3 \mathrm{~m} \mathrm{~s}^{-1}$. However, in some models these maximum wind speeds originate from a region of wave breaking between $10 \mathrm{~km}$ and $12 \mathrm{~km}$ and are not related to the downdraught region on the leeward side of the mountain. In the latter region, the agreement among the models is reasonable with maximum wind speeds of approximately $23 \mathrm{~m} \mathrm{~s}^{-1}$ in COSMO, $24 \mathrm{~m} \mathrm{~s}^{-1}$ in UWNMS and $27 \mathrm{~m} \mathrm{~s}^{-1}$ in WRF. According to Durran and Klemp (1983), one would expect that the remaining water vapour in the model simulations would lead to a damping of the gravity wave amplitude and to lower horizontal wind speeds especially in the WRF simulation. Since the opposite is the case, the differences among the models in terms of horizontal wind speeds are caused by differences in either the numerical time integration scheme or the dynamical setup (e.g., depth of the Rayleigh damping layer, damping coefficients, upper model boundary condition) and not by the remaining moisture content on the leeward side of the mountain. Nevertheless, the maximum deviations of the mean horizontal wind velocities are below $0.5 \mathrm{~m} \mathrm{~s}^{-1}$ among the models.

The vertical wind speeds are generally in good agreement with the maximum wind speeds increasing throughout the simulation from approximately $0.5 \mathrm{~m} \mathrm{~s}^{-1}$ after initial spinup to approximately $0.8-1.0 \mathrm{~m} \mathrm{~s}^{-1}$ after $10 \mathrm{~h}$. The maximum spread among the models does not exceed $0.2 \mathrm{~m} \mathrm{~s}^{-1}$ in terms 
of maximum vertical velocities and is well below $1.0 \mathrm{~cm} \mathrm{~s}^{-1}$ for the mean vertical wind velocities.

In the simulation SIM_2_CC the initial sea level temperature is decreased in comparison to the simulation SIM_1_CC which leads to lower values of the maximum specific humidity of approximately $4.7 \mathrm{~g} \mathrm{~m}^{-3}$. However, the horizontal and vertical wind velocities change only marginally in response to the decreased specific humidity and are comparable to the wind velocities of simulation SIM_1_CC (not shown).

In the simulations with increased aerosol number concentrations SIM_1_PC and SIM_2_PC, respectively, the horizontal and vertical wind velocities change slightly due to dynamical feedbacks of aerosol-cloud-precipitation interactions (not shown) but these differences are much smaller than the differences between the individual model simulations and, thus, are not investigated further.

\subsubsection{Clouds and precipitation comparison}

Despite the reasonable agreement of the dynamical states of the model considerable differences exist among the models in terms of cloud structure, cloud microphysics and precipitation. All models simulate an orographic cloud attached to the upstream side of the mountain and an upper-level orographic wave cloud in a region of wave breaking on the leeward side of the mountain. Figures 4 and 5 show the cloud fields for the simulation SIM_1_CC for all models averaged over the $10 \mathrm{~h}$ simulation time.

The average depth of the upstream cloud varies among the models between approximately $3.5 \mathrm{~km}$ (WRF) and $5 \mathrm{~km}$ (UWNMS) (Fig. 4). Considerable discrepancies exist in the partitioning between the liquid and the ice in the upstream orographic cloud. For example, COSMO and UWNMS both simulate cloud layers with sustained mixed-phase conditions sandwiched by a partly supercooled liquid cloud at lower levels and a pure ice cloud aloft. However, the mixed-phase cloud layers are deeper in COSMO than in UWNMS. In contrast, the entire cloud consists of liquid with cloud water mixing ratios up to approximately $0.6 \mathrm{~g} \mathrm{~m}^{-3}$ in the WRF simulations. Due to the lack of ice in the WRF simulation, the WRF model produces also deeper cloud water fields than the other models (Fig. 5).

The cloud droplet number concentrations are in reasonable agreement among the models with values on the order of $100 \mathrm{~cm}^{-3}$ but maximum values ranging from $70 \mathrm{~cm}^{-3}$ (WRF) to almost $140 \mathrm{~cm}^{-3}$ (COSMO). The higher maximum cloud droplet number concentrations in COSMO are related to the higher vertical velocities on the upslope side of the mountain in the COSMO simulation. The mean cloud droplet size averaged over the $10 \mathrm{~h}$ simulation ranges from approximately $17 \mu \mathrm{m}$ (COSMO) to $22 \mu \mathrm{m}$ (UWNMS). Ice crystal number concentrations are on the order of roughly $1001^{-1}$ in the upstream cloud in all models.

Despite the reasonable agreement in the cloud droplet number concentrations there exists remarkable variability among the models with respect to the mass mixing ratios of the different hydrometeor types (Fig. 5). COSMO and UWNMS both show contributions from cloud liquid and cloud ice at lower levels but the contributions from the ice phase are considerably higher in UWNMS than in COSMO.

The differences in the liquid to ice mass partitioning in the orographic cloud also affect the development of precipitable hydrometeors. For example, WRF shows mainly contributions from rain and snow with negligible small contributions from graupel. In COSMO and UWNMS precipitation shows contributions from snow generated in the upper regions of the cloud as well as graupel and rain in the lower levels of the clouds. These differences suggest that in WRF coalescence of cloud droplets is the dominant mechanism responsible for rain formation as compared to other microphysical processes. In COSMO and UWNMS contributions from frozen hydrometeors to rain formation are dominant. These frozen hydrometeors are generated aloft, start melting below the freezing level and eventually lead to rain. Due to the diminishing role of the ice phase the coalescence process is more important for the rain formation in the WRF simulation than it is in the other models. Furthermore, COSMO and UWNMS produce considerable amounts of snow from aggregation of ice crystals and graupel is produced by riming in regions with sufficient supercooled liquid water. These differences in the precipitable hydrometeor fields have implications for the amount and distribution of orographic precipitation as will be discussed later.

The upper-level wave clouds are similar among the models but cloud fields vary regarding the ice water content and the spatial extent of the cloud. The maximum ice water mixing ratios agree reasonably between COSMO and UWNMS but are slightly smaller in WRF. The horizontal cloud extent of the upper-level wave cloud is largest in UWNMS. These discrepancies are attributable to the production of smaller ice crystals with inherently smaller terminal fall velocities in UWNMS and the different ice aggregation efficiencies used in the models. For example, in the COSMO simulation snow develops in the upper-level cloud whereas there is no snow in the WRF and UWNMS simulations in this region. However, the differences in the upper-level cloud are not of further interest here because the contribution of this cloud to the orographic precipitation in the models is negligibly small.

Figure 6 shows the time series of liquid water path (LWP) and ice water path (IWP) in the models averaged over the mountain slopes (i.e., all grid points located within $40 \mathrm{~km}$ up and downstream of the mountain peak) for simulation SIM_1_CC.

The time series confirms that WRF is lacking ice compared to the other models and that liquid water is dominant during the simulation. In contrast, COSMO and UWNMS both show lower LWP but higher IWP and, thus, sustain more ice in the upstream orographic cloud.

Figure 7 shows the cloud droplet and ice crystal number concentrations for the simulation with increased aerosol 

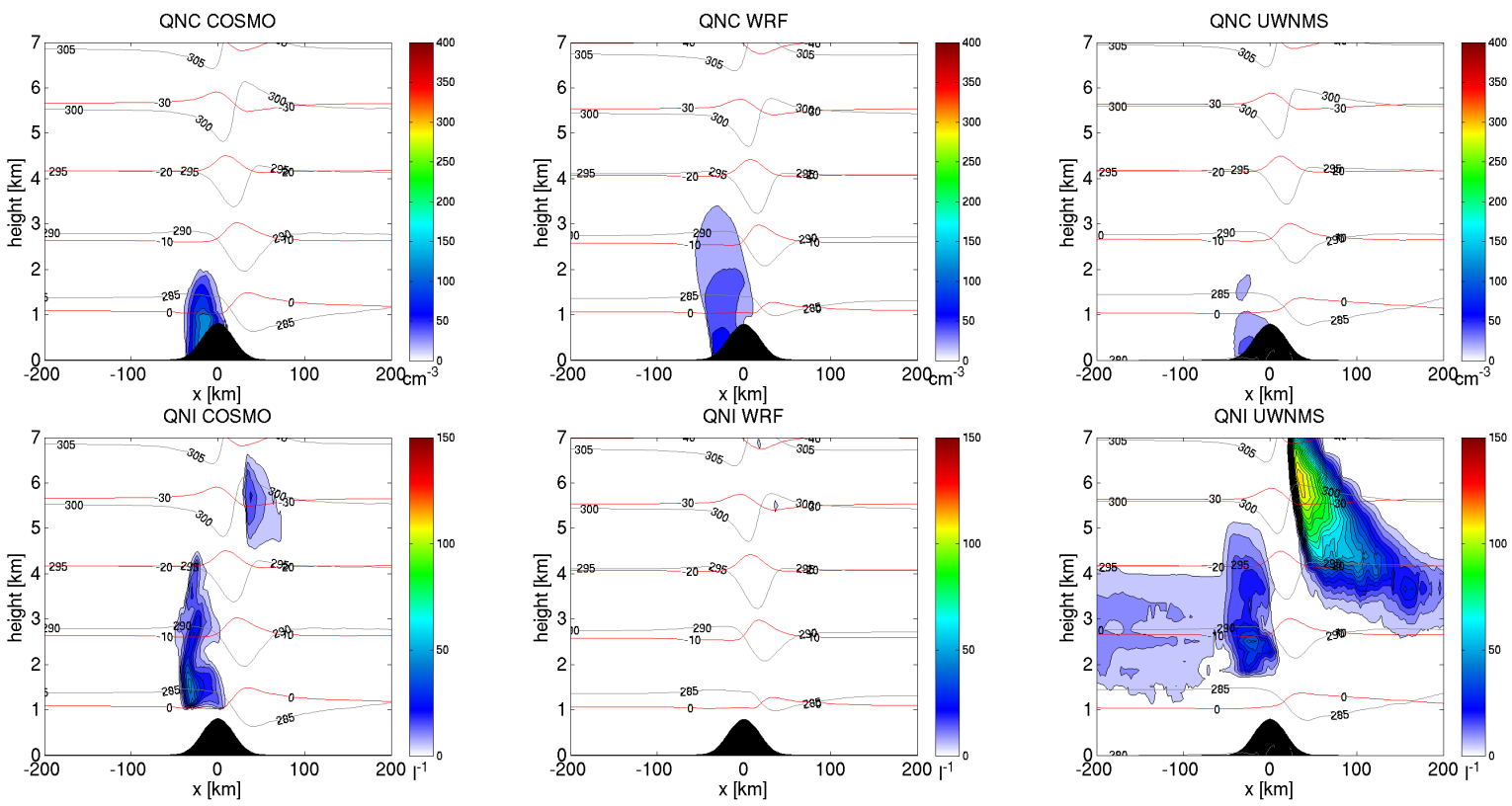

Fig. 4. Vertical cross section of number concentrations of cloud droplets (QNC) and ice crystals (QNI) for COSMO, WRF and UWNMS averaged over $10 \mathrm{~h}$ simulation. The contour lines show the temperature (red) and the potential temperature (grey). Units are $\mathrm{cm}^{-3}$ for cloud droplets and $1^{-1}$ for ice crystals, ${ }^{\circ} \mathrm{C}$ for temperature and $\mathrm{K}$ for potential temperature. Only part of the computational domain is shown.

number concentration SIM_1_PC averaged over the $10 \mathrm{~h}$ simulation time.

In SIM_1_PC the cloud droplet number concentrations are increased in all models but the variability among the models is larger than in the simulation SIM_1_CC with cloud droplet number concentrations ranging from approximately $150 \mathrm{~cm}^{-3}$ (WRF) to almost $440 \mathrm{~cm}^{-3}$ (COSMO). The mean cloud droplet size averaged over the $10 \mathrm{~h}$ simulation decreases relative to the clean case simulation SIM_1_CC in all models. In contrast, there is only little change in the ice crystal number concentrations compared to the clean case simulation SIM_1_CC. However, the result that the ice crystal number concentrations are not much affected in the simulations may be related to the oversimplified treatment of heterogeneous ice nucleation and in particular to the fact that the ice initiation is independent from the aerosol chemical properties.

The differences in the LWP and the IWP between the low aerosol simulation SIM_1_CC and the high aerosol simulation SIM_1_PC are shown in Fig. 8.

Despite the considerable variability of the microphysical properties of the simulated orographic cloud all models agree qualitatively on the result that on average the LWP is increased with increasing aerosol number concentrations but there is little quantitative agreement. Regarding the IWP all models show slight changes throughout the $10 \mathrm{~h}$ simulation but on average changes in IWP are generally small and positive for WRF but negative for COSMO and UWNMS.
Table 4. Inter-model comparison of the total precipitation $(\mathrm{mm})$ for the set of simulations in Table 2 after $10 \mathrm{~h}$ simulation.

\begin{tabular}{lccc}
\hline Simulation & COSMO & WRF & UWNMS \\
\hline SIM_1_CC & 459 & 104 & 466 \\
SIM_1_PC & 409 & 84 & 461 \\
SIM_2_CC & 409 & 143 & 430 \\
SIM_2_PC & 393 & 136 & 432 \\
SIM_3_CC & 2168 & 2124 & 2047 \\
SIM_3_PC & 2111 & 2062 & 2029 \\
SIM_4_CC & 1438 & 1502 & 1353 \\
SIM_4_PC & 1427 & 1495 & 1352 \\
\hline
\end{tabular}

The intercomparison of precipitation is shown in Fig. 9 for the simulation SIM_1_CC.

The orographic precipitation is in good agreement in COSMO and UWNMS regarding the peak and the shape of the precipitation distribution as well as the total precipitation in the domain (see Table 4).

In all models orographic precipitation maxima are found on the upslope side of the mountain with slight displacements of the peaks towards the top of the mountain in the WRF simulation. However, the amount of peak and total precipitation simulated by WRF is much smaller than in the other models which implies that the precipitation regime simulated by WRF is less efficient than in both of the other models. Furthermore, there is generally little agreement among the models on how different hydrometeor categories contribute to the 

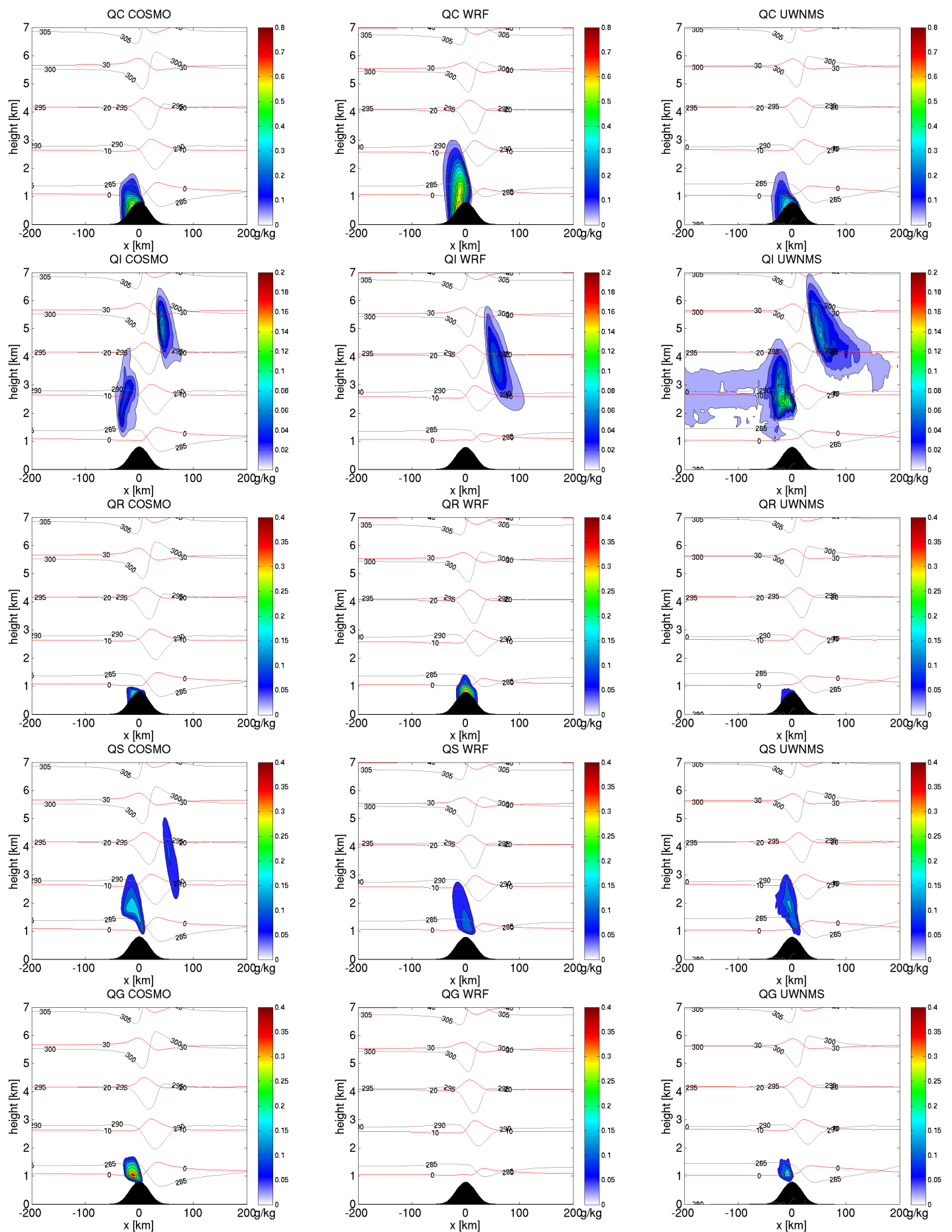

Fig. 5. Same as Fig. 4 but for the mass mixing ratios (units $\mathrm{g} \mathrm{kg}^{-1}$ ) of cloud water (QC), ice (QI), rain (QR), snow (QS) and graupel (QG).

overall precipitation distribution. For example, precipitation at the surface originates almost entirely from rain in the WRF simulation whereas the other models also show contributions from graupel (and snow in the case of UWNMS). Most of the total precipitation in COSMO is made up of rain with some but little contribution from graupel whereas in UWNMS the contribution from graupel is much stronger. Moreover, the fallout of graupel is faster in UWNMS and occurs already on the upslope side of the mountain whereas in COSMO the precipitation distribution of graupel is centred around the mountain peak. The relative shift in the precipitation from graupel is mainly caused by differences in the terminal fall 

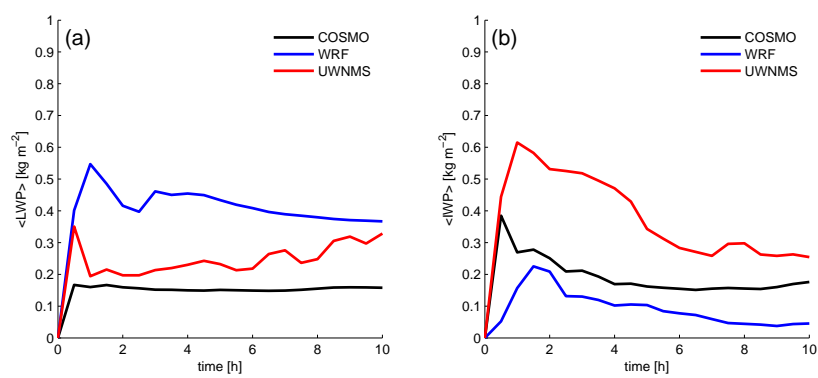

Fig. 6. Time series of liquid water path (LWP) in panel (a) and ice water path (IWP) in panel (b) averaged over the mountain slopes (horizontal distances -40 to $40 \mathrm{~km}$ ). Note that LWP includes liquid water from cloud droplets and rain and IWP includes ice crystals, snow and graupel.

velocities of graupel used in the models but to some extent also due to the varying strength of the simulated ice phase and the thresholds used to convert rimed snow flakes to graupel. However, the bottom line of the inter-comparison of simulation SIM_1 is that the presence of ice in the upper part of the upstream orographic cloud and the sustained mixedphase conditions lead to a more efficient precipitation regime (i.e., a seeder-feeder cloud type) in COSMO and UWNMS with more upslope precipitation and considerable contributions from rimed crystals (i.e., graupel). Increasing aerosol number concentrations in simulation SIM_1_PC leads qualitatively to a reduction of total domain precipitation in all models but the sensitivities vary greatly among the models. WRF depicts the highest sensitivity of precipitation to the aerosol perturbation mainly due to a considerable reduction in rain formation and little contributions from ice-phase hydrometeors. The sensitivity of the warm rain production is weaker in the case of COSMO and UWNMS. The contribution to rain in the simulations are dominated by the melting of frozen hydrometeors formed aloft. However, relative to COSMO and UWNMS the rain formation in WRF is more dependent on the warm-phase coalescence process. Furthermore, COSMO and UWNMS show increases in graupel which partly compensate for the loss caused by the reduction of rain. Hence, the high sensitivity of WRF to changes in aerosol number may be explained by the diminishing role of the ice phase and the lack of graupel formation in this specific simulation. Overall, WRF shows the highest sensitivity with a total precipitation reduction of approximately $19 \%$ compared to the clean case simulation but also shows the smallest total precipitation amounts. COSMO and UWNMS both simulate more precipitation and depict weaker sensitivities with respect to changes in aerosol number concentration of $11 \%$ and $1 \%$, respectively (see Table 4 for details). All models except UWNMS tend to simulate higher values of SP meaning that relative to the low aerosol simulation more precipitation is falling on the leeward side of the mountain in the high aerosol simulation (see Table 5 for details).
Table 5. Inter-model comparison of the spillover for the set of simulations in Table 2. The spillover is defined as the ratio of leeward precipitation to total precipitation.

\begin{tabular}{lccc}
\hline Simulation & COSMO & WRF & UWNMS \\
\hline SIM_1_CC & 0.30 & 0.53 & 0.32 \\
SIM_1_PC & 0.32 & 0.57 & 0.31 \\
SIM_2_CC & 0.24 & 0.63 & 0.31 \\
SIM_2_PC & 0.27 & 0.66 & 0.30 \\
SIM_3_CC & 0.19 & 0.23 & 0.16 \\
SIM_3_PC & 0.23 & 0.23 & 0.18 \\
SIM_4_CC & 0.12 & 0.11 & 0.13 \\
SIM_4_PC & 0.13 & 0.13 & 0.13 \\
\hline
\end{tabular}

Table 6. Inter-model comparison of the drying ratio for the set of simulations in Table 2. The drying ratio is defined as the ratio of horizontally integrated total precipitation flux at the surface to the vertically integrated water vapour influx.

\begin{tabular}{lccc}
\hline Simulation & COSMO & WRF & UWNMS \\
\hline SIM_1_CC & 0.12 & 0.06 & 0.13 \\
SIM_1_PC & 0.11 & 0.04 & 0.13 \\
SIM_2_CC & 0.18 & 0.12 & 0.19 \\
SIM_2_PC & 0.18 & 0.11 & 0.19 \\
SIM_3_CC & 0.59 & 0.62 & 0.54 \\
SIM_3_PC & 0.58 & 0.60 & 0.53 \\
SIM_4_CC & 0.68 & 0.78 & 0.60 \\
SIM_4_PC & 0.68 & 0.79 & 0.60 \\
\hline
\end{tabular}

DR tends to decrease with increasing aerosol number concentration and the relative magnitude of the changes are ranked according to the decrease in total precipitation in the individual model simulations. Hence, relative changes in DR are more pronounced in WRF than in COSMO whereas in UWNMS DR is virtually unchanged (see Table 6 for details).

\subsubsection{Microphysics comparison}

Comparing the microphysical processes among the models elucidates why the models disagree on the contributions of precipitation from rain and graupel and sheds some light on why the sensitivities with respect to aerosols are different.

Figure 10 shows the amount of liquid and ice mass density that is converted to precipitable hydrometeors through the microphysical processes coalescence, aggregation, riming and diffusional growth. In UWNMS and WRF diffusional growth is by far the dominant microphysical process and all processes involving collections are smaller. Contrary, in COSMO the contributions from diffusional growth and riming are of comparable magnitude. In the models where substantial amounts of ice are present, riming is the most important collection process and overpowers contributions from aggregation and coalescence. In simulation Sim_1 all 

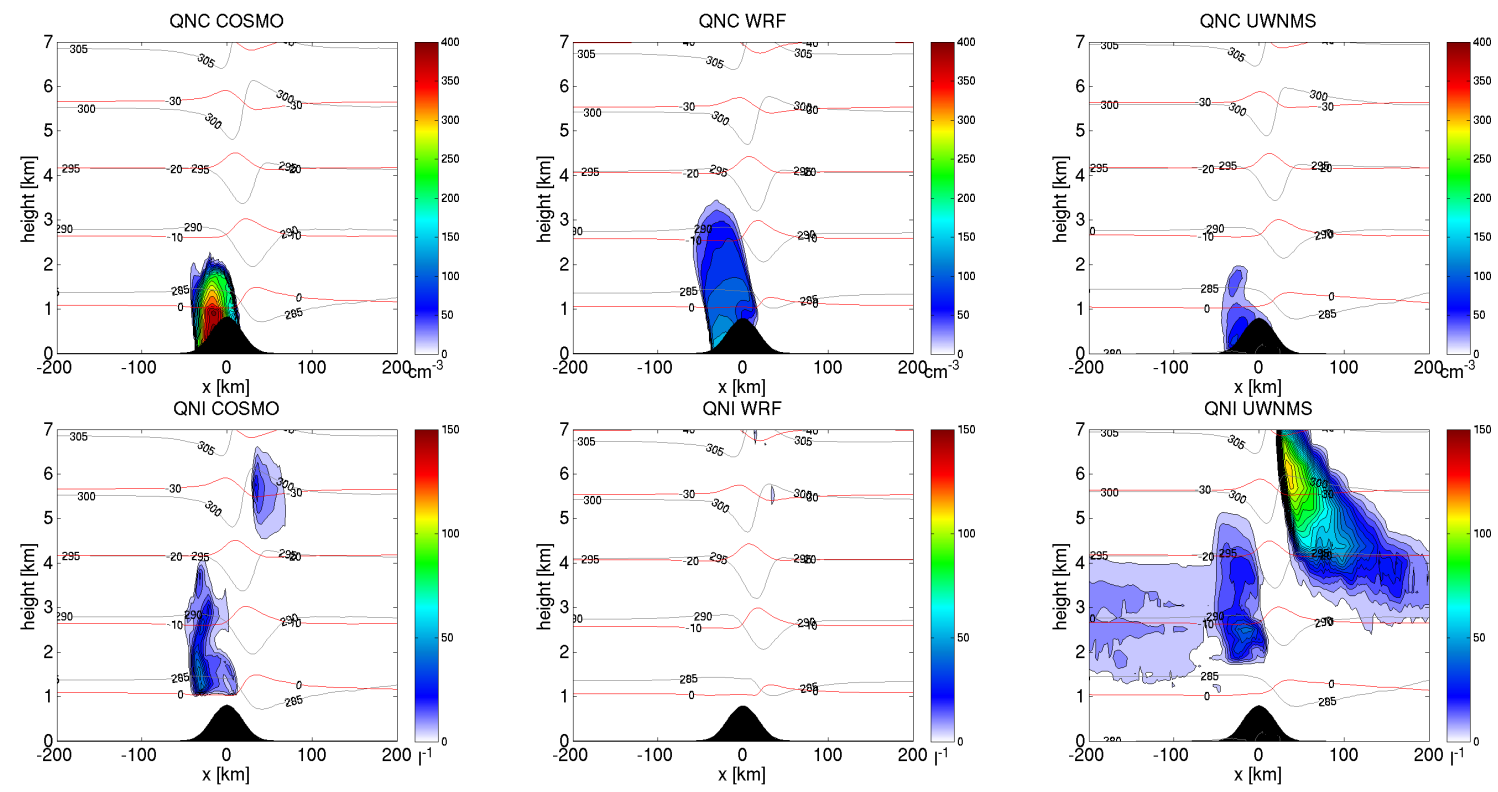

Fig. 7. Same as Fig. 4 but for the polluted case simulation SIM_1_PC.
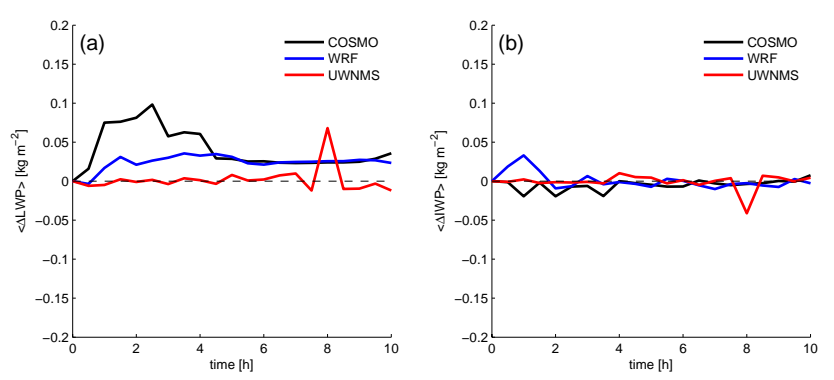

Fig. 8. Same as Fig. 6 but for the difference between the polluted case and the clean case in simulation SIM_1. The thin black dashed line indicates the zero line.

models agree on the result that the net diffusional growth decreases with increasing aerosol number concentrations due to enhanced evaporation of the smaller cloud droplets and rain drops. In COSMO and UWNMS riming is the dominant collection process and the riming rates are increased if the aerosol number concentrations are increased. As a consequence, the amount of precipitation from graupel is increased with increasing aerosol number concentrations in both models. In contrast, in the WRF simulation the contributions from riming, aggregation and coalescence are comparable and riming is decreased if the aerosol number concentrations are increased. Furthermore, aggregation is increased in the simulations with high aerosol number concentrations in COSMO and WRF but is slightly decreased in the UWNMS simulation. All models indicate a decrease in the coalescence if the aerosol number concentrations are increased but disagree on the importance of coalescence process relative to other microphysical processes. COSMO and UWNMS show a comparably weak contribution to precipitation from the coalescence process whereas in WRF coalescence is more important as the contributions of ice phase processes are less significant. Furthermore, the decrease in coalescence is rather subtle in the case of UWNMS because the reduction in the cloud droplet coalescence is almost completely offset by the accretion of cloud droplets by rain. Thus, the accretion by rain may be an important microphysical process with the potential to reduce the overall sensitivity of the cloud droplet coalescence process in mixed-phase clouds if rain drops can be produced by melting.

\subsection{Sensitivity studies with respect to temperature}

In the second set of simulations (SIM_2_CC and SIM_2_PC) the same dynamical regime is simulated with a colder surface temperature in the initial thermodynamical profile (see Fig. 1 and Table 2 for details). The dynamical states of the models are only marginally affected by this temperature change and the inter-model comparison is similar to the previous set of simulations. As in the previous set of simulations, all models show on average an increase in LWP in the simulations with higher aerosol number concentrations but only little change in the IWP.

Figure 11 shows the comparison of precipitation for the set of simulations with colder surface temperature SIM 2 _CC and SIM_2_PC. The variability among the models in the orographic precipitation distribution is larger than in the warm set of simulations with little agreement regarding the shape of the precipitation distribution or the amount of precipitation. Total precipitation is highest in UWNMS and lowest in 

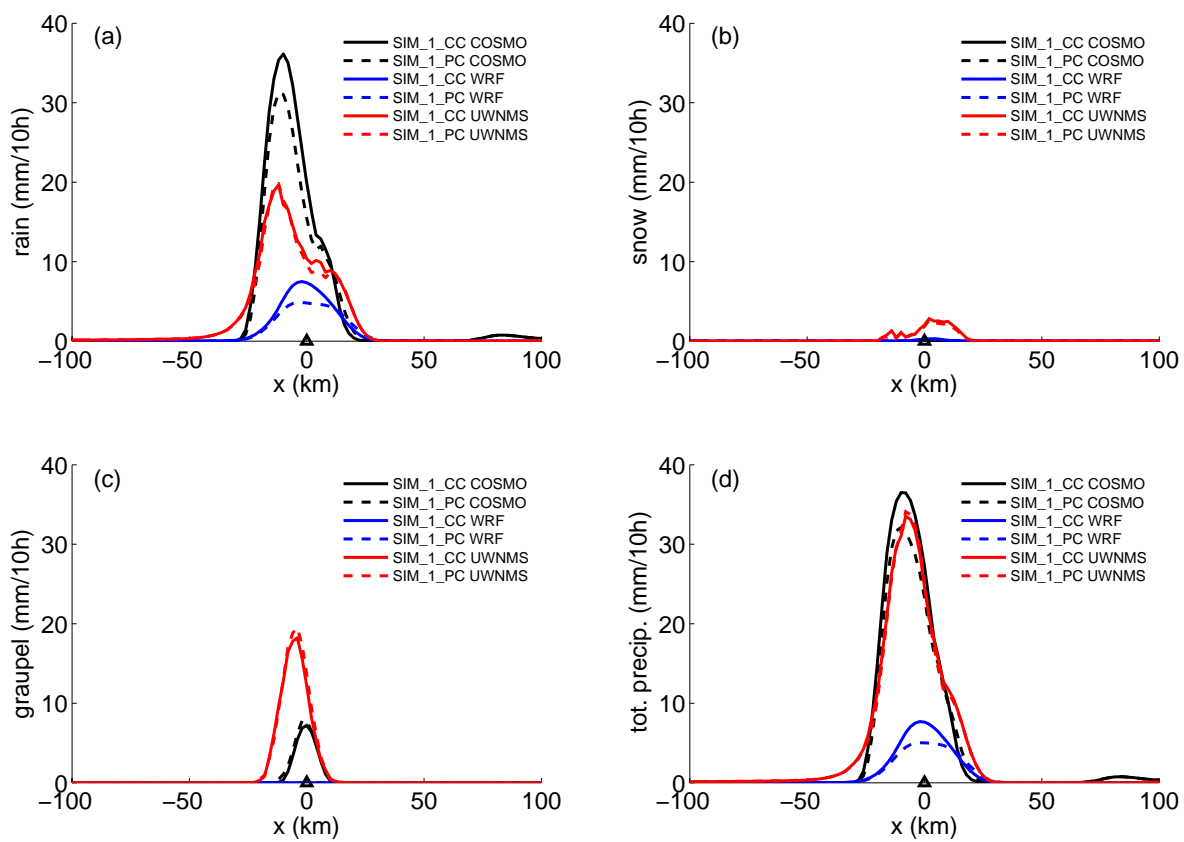

Fig. 9. Orographic precipitation distribution for the simulations SIM_1_CC (solid) and SIM_1_PC (dashed) for rain (a), snow (b), graupel (c) and total precipitation (d) after $10 \mathrm{~h}$ simulation time. The individual models shown are COSMO (black), WRF (blue) and UWNMS (red).
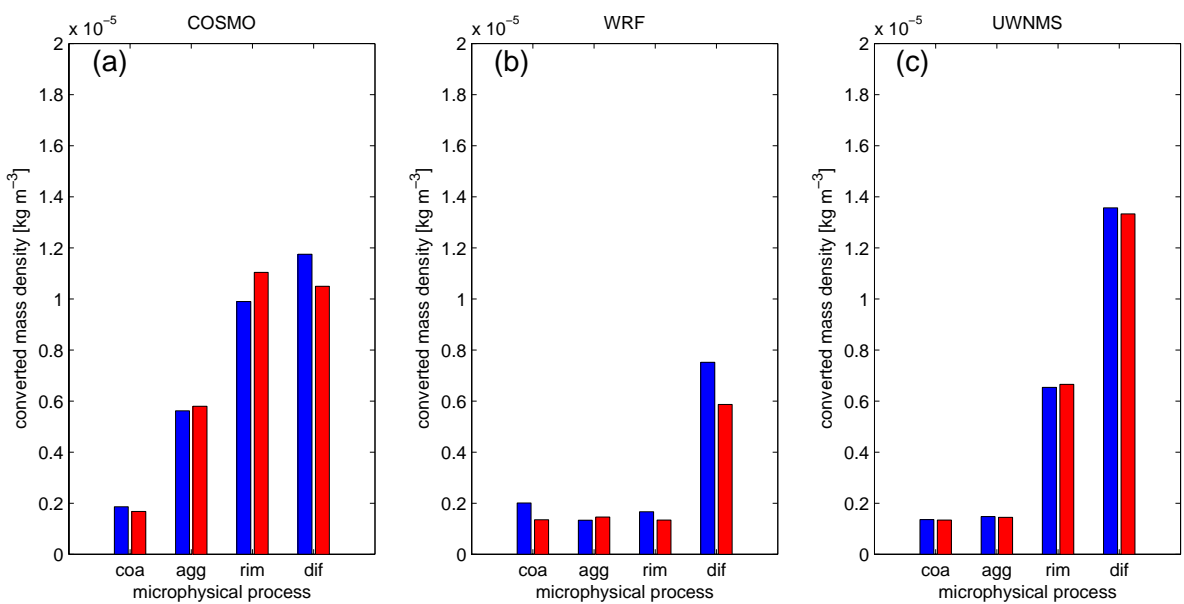

Fig. 10. Mass density of cloud liquid and ice converted to precipitable hydrometeors by coalescence (coa), aggregation (agg), riming (rim) and diffusional growth (dif) for the clean case simulation SIM_1_CC (blue) and the polluted case simulation SIM_1_PC (red) in COSMO (a), WRF (b) and UWNMS (c). In the bulk microphysics schemes, where cloud droplets and rain drops are artificially differentiated according to size, the coalescence term includes contributions from autoconversion and accretion. The diffusional growth term includes condensation, deposition, evaporation and sublimation. All values are integrated over the $10 \mathrm{~h}$ simulation time.

WRF. However, the spatial precipitation distribution is more narrow for COSMO than for the other models which leads to the highest peak precipitation rates. Most of the precipitation reaches the surface in form of snow and graupel and none of the models produces any significant amount of rain. As in the previous case, there is little agreement on the partitioning of precipitation to snow or graupel which in turn explains the discrepancies in the simulated precipitation dis- tribution. These discrepancies are also reflected in the microphysical comparison of the models (see Fig. 12). Similar to the previous case diffusional growth is dominant in all models. In COSMO and UWNMS aggregation overpowers riming and most of the precipitation is from snow flakes. On the contrary, in the WRF simulation riming dominants aggregation but the rimed snow flakes are not converted to graupel as in the other models. Contributions from the coalescence 

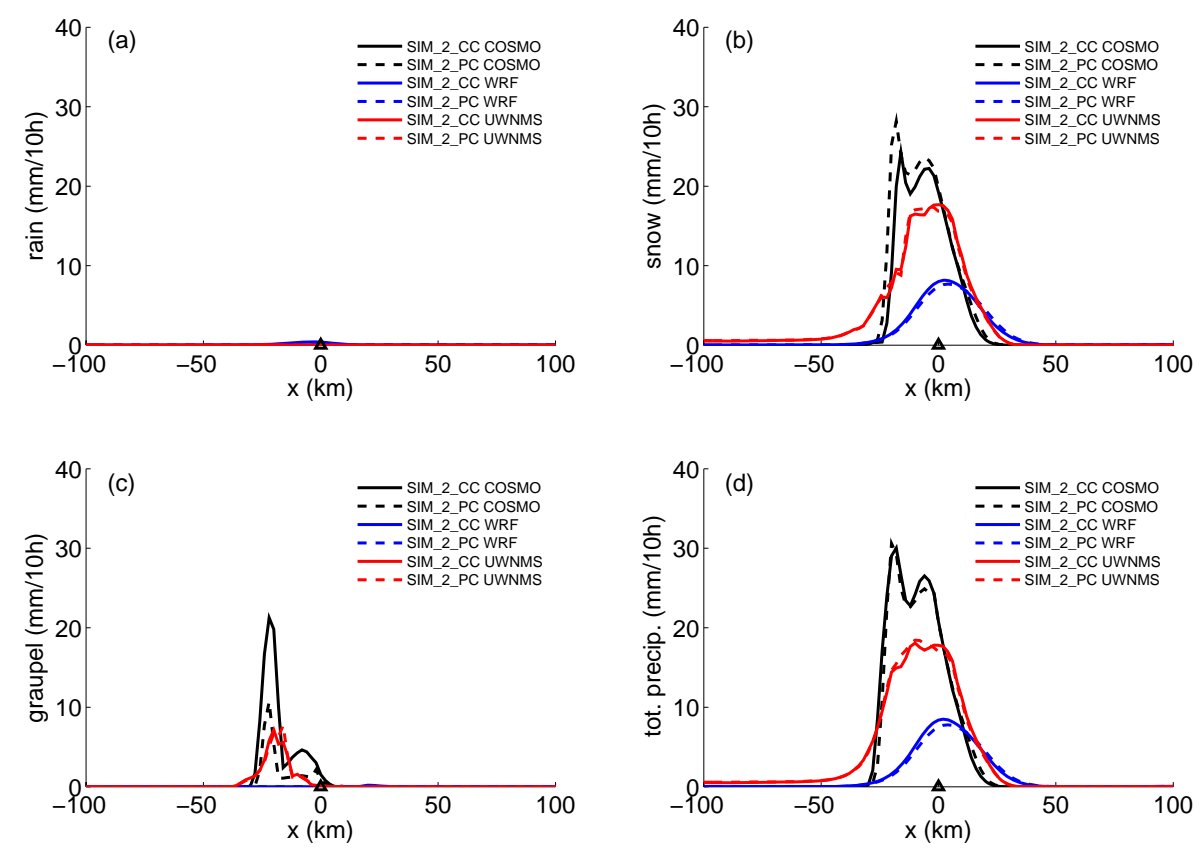

Fig. 11. Same as Fig. 9 but for the clean case simulation SIM_2_CC (solid) and the polluted case simulation SIM_2_PC (dashed), respectively.
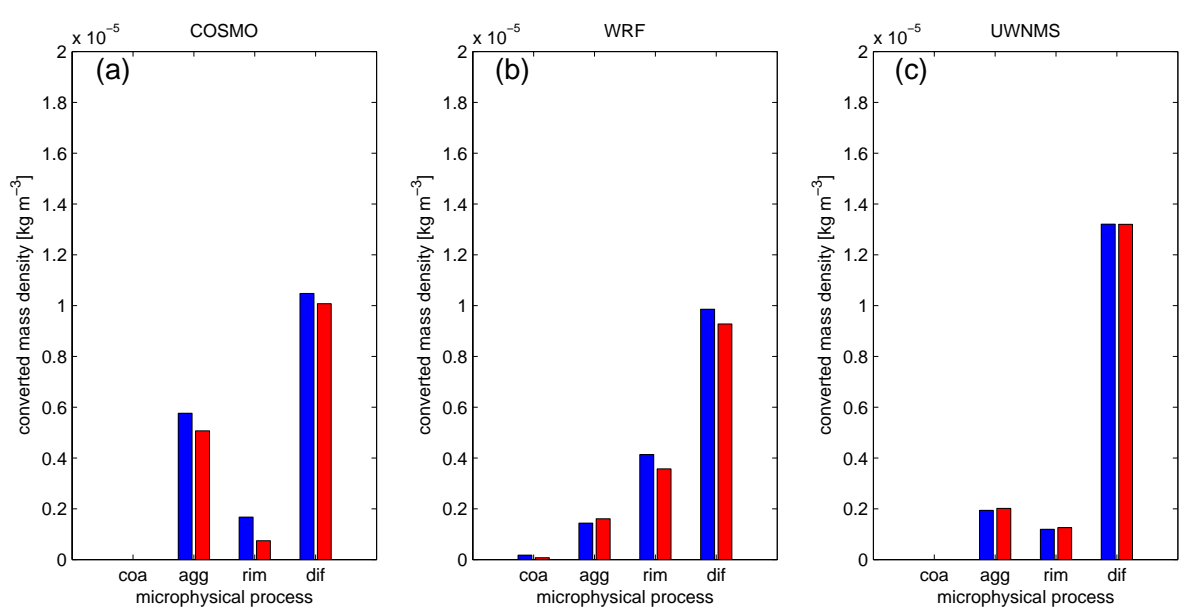

Fig. 12. Same as Fig. 10 but for the clean case simulation SIM $\_$_CC (blue) and the polluted case simulation SIM $\_2$ PC (red), respectively.

process are negligible in all models. Riming is decreased in COSMO and WRF but is slightly increased in UWNMS.

The sensitivity of orographic precipitation to changes in the aerosol number concentrations as simulated by the models is generally weaker than in the previous simulations with warmer temperatures (see Table 4 for details). In COSMO and WRF total precipitation is decreased by $4 \%$ and $5 \%$, respectively, whereas in UWNMS total precipitation budgets are virtually unchanged (a subtle increase). COSMO and WRF both show higher values of SP in the high aerosol simulation meaning that some of the precipitation (i.e., snow in this particular case) is redistributed towards the leeward side of the mountain. The DR is only little affected according to the change in the precipitation budgets of the models.

\subsection{Simulations of orographic precipitation with flow blocking}

In the next set of simulations (SIM_3, SIM_4) the height of the mountain is increased while the thermodynamical initial conditions are kept constant. This generates a flow regime with upstream flow blocking and severe downslope winds on the leeward side of the mountain.

\subsubsection{Dynamics comparison}

Figure 13 shows a comparison of the time evolution of the specific humidity and wind speeds in the models. Generally, the differences in maximum horizontal and vertical wind 

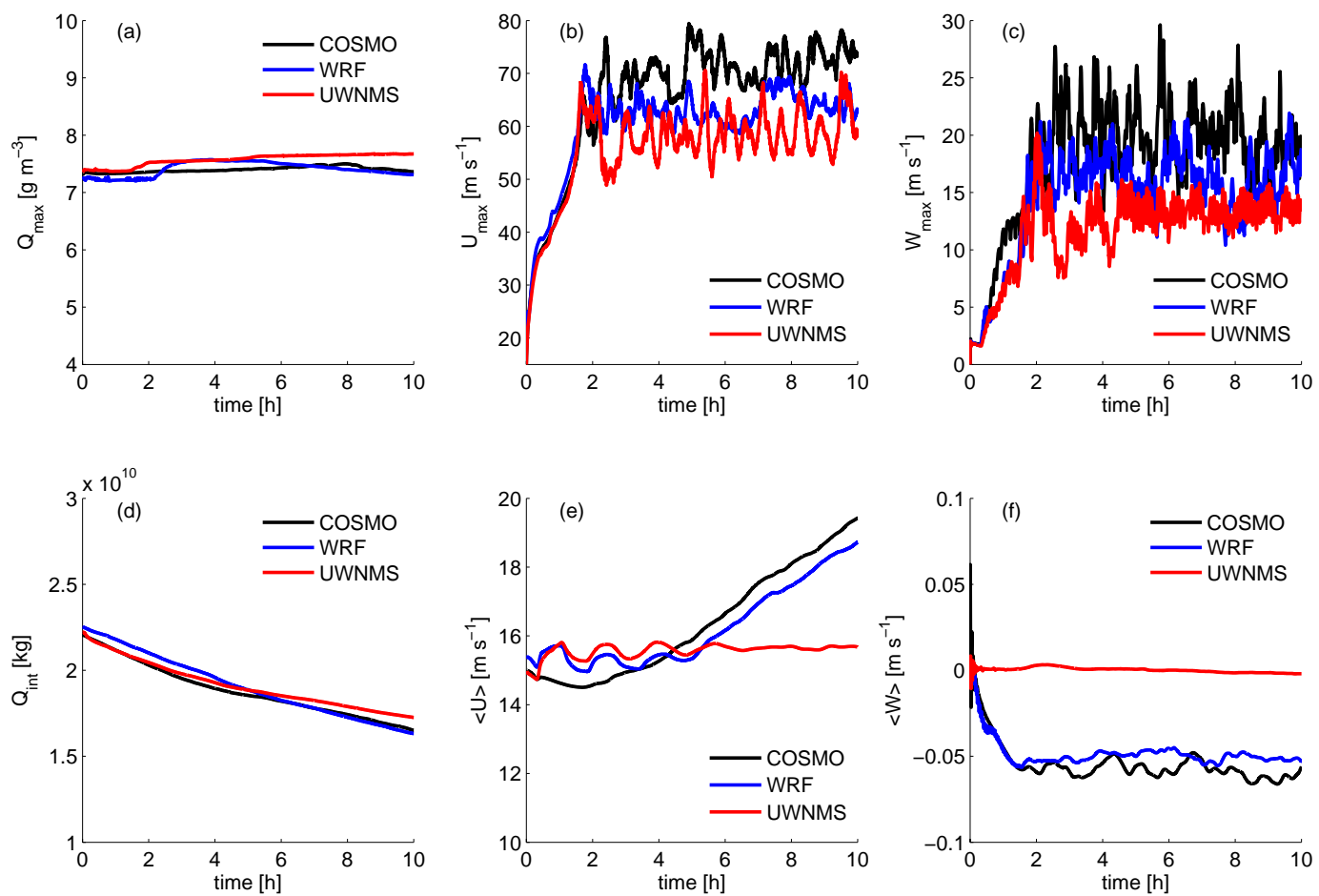

Fig. 13. Same as Fig. 3 but for simulation SIM_3_CC.
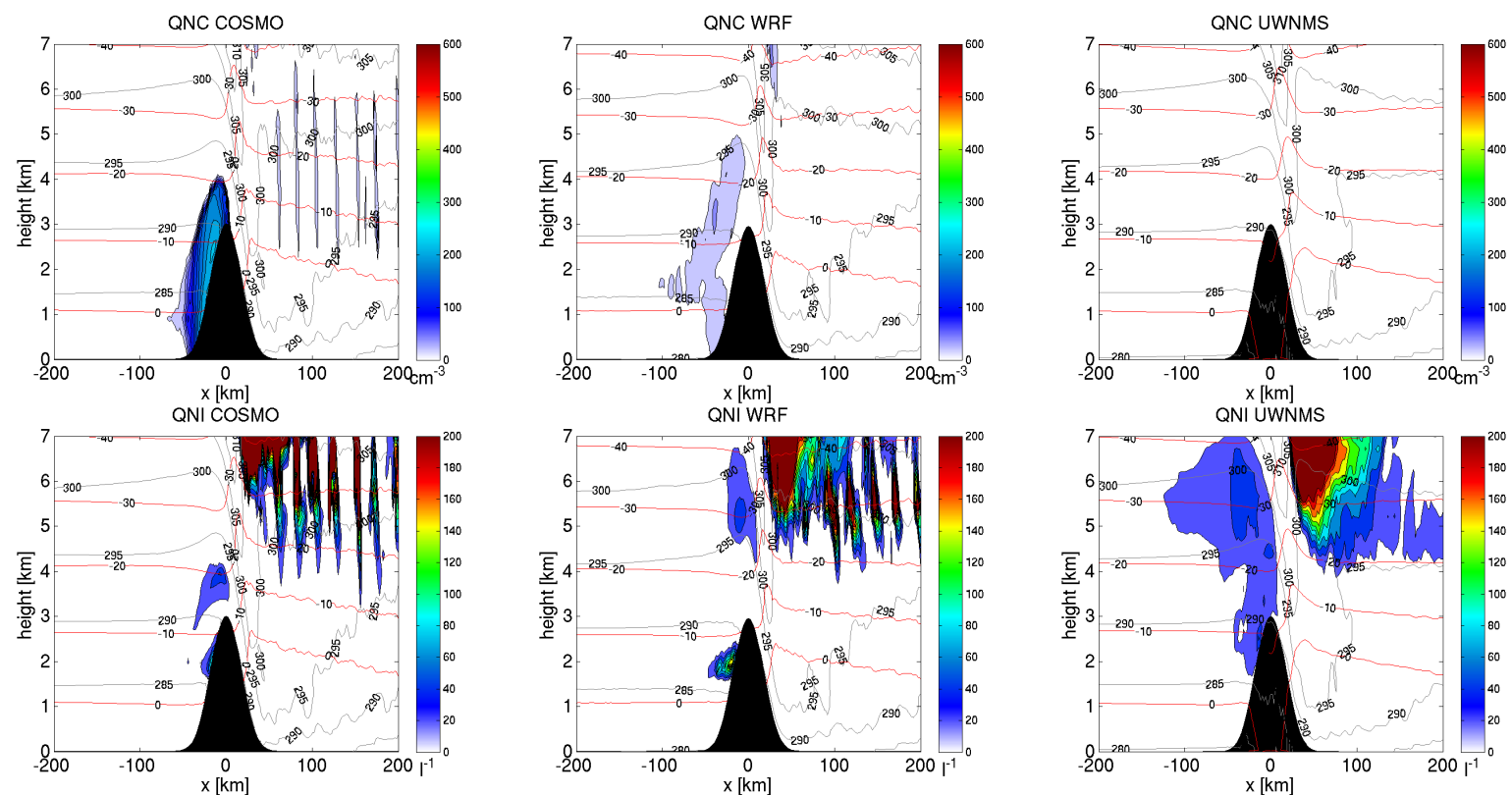

Fig. 14. Same as Fig. 4 but for simulation SIM_3_CC. 

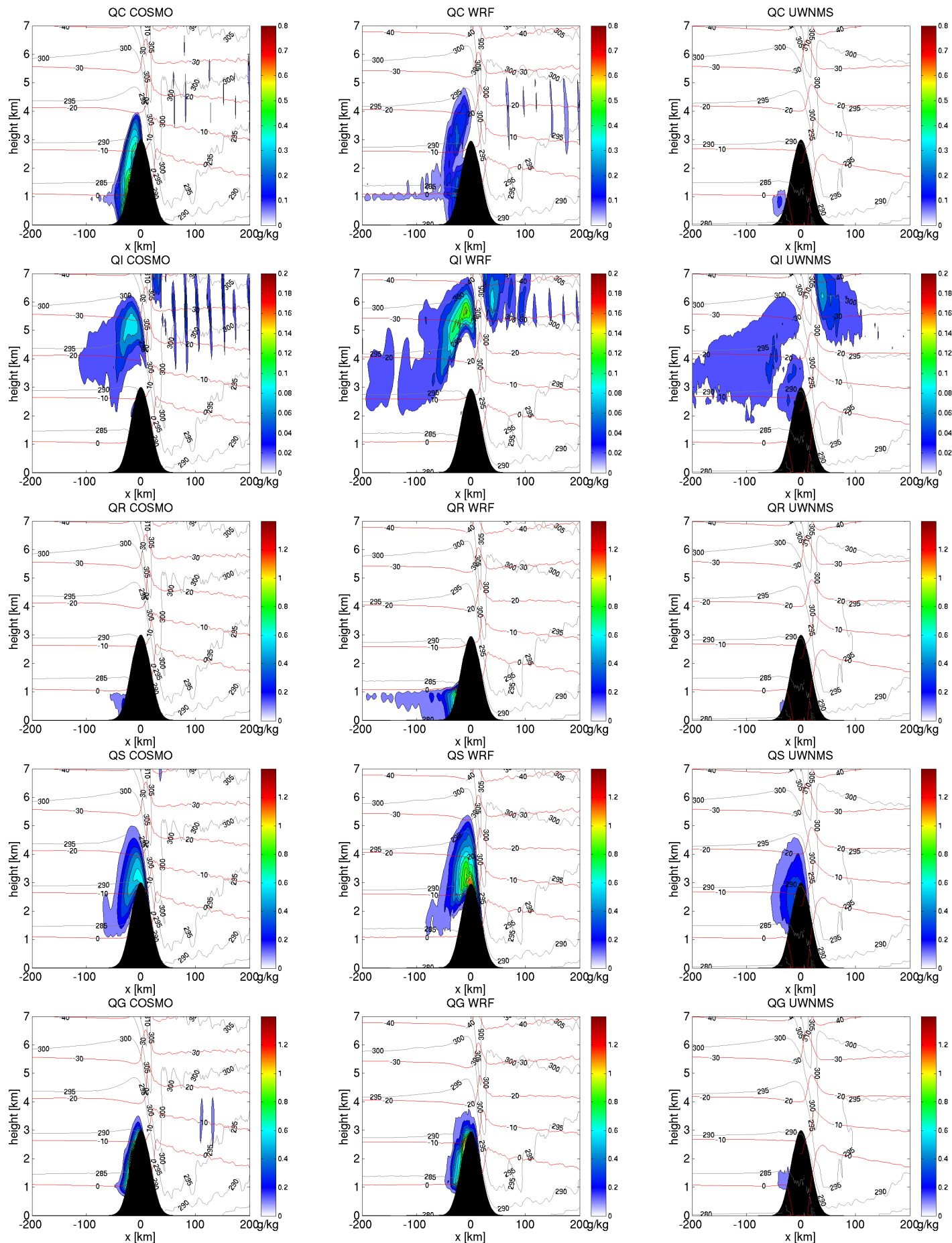

Fig. 15. Same as Fig. 5 but for simulation SIM_3_CC.

speeds are much higher in this case than in the unblocked flow case because the downslope winds on the leeward side of the mountain and the regions of wave breaking are very turbulent. The largest differences in maximum and minimum wind speeds occur in the regions of downslope winds on the leeward side of the mountain below ridge height and in the zones of wave breaking aloft. The strength of the downslope winds and the breaking waves are to a large extent controlled by the amount of precipitation on the upstream side of the mountain and the water vapour budgets of the models. Nevertheless, the winds on the upstream side of the mountain are in relatively good agreement and these are the ones that are 

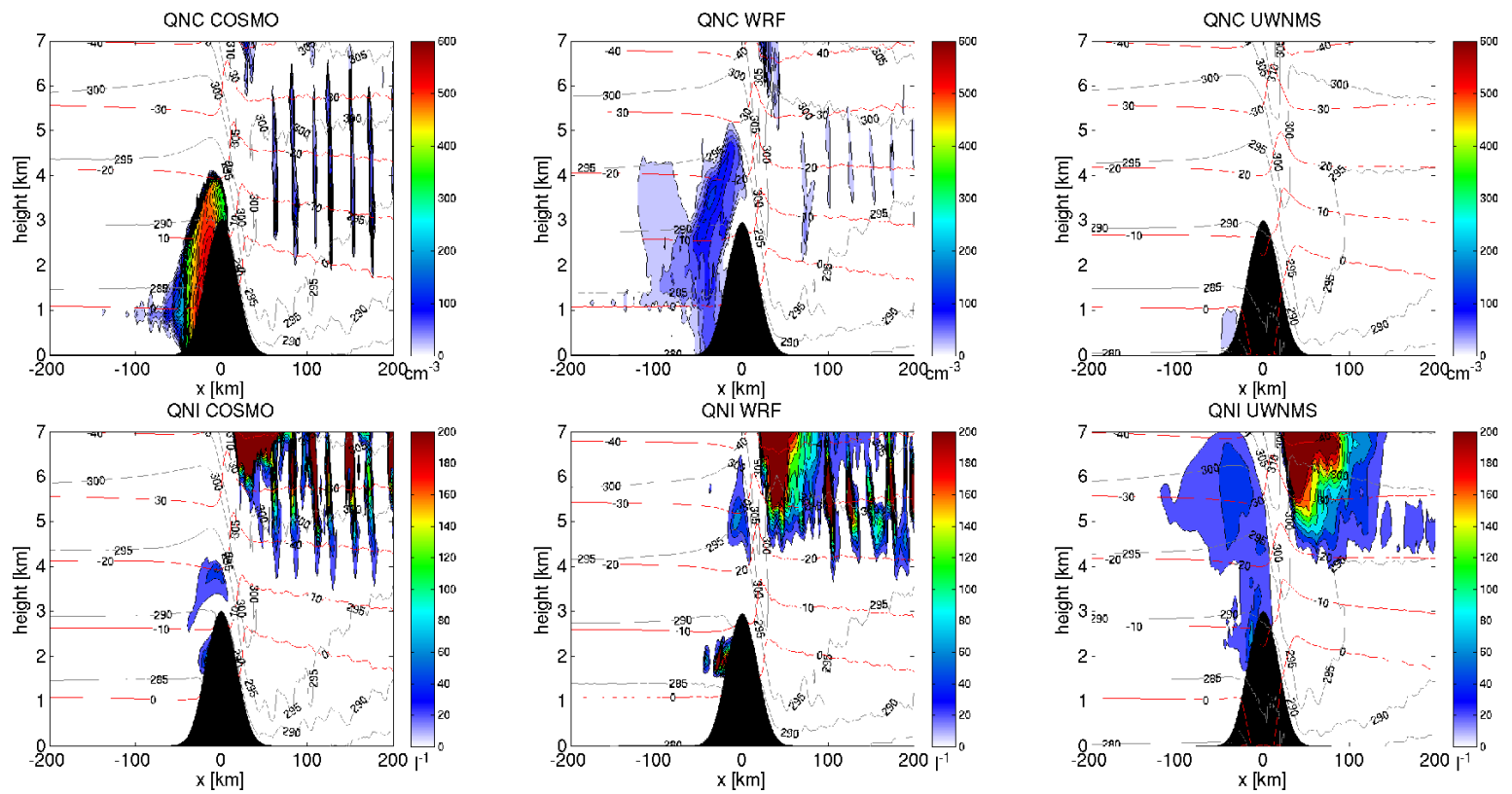

Fig. 16. Same as Fig. 7 but for simulation SIM_3_PC.
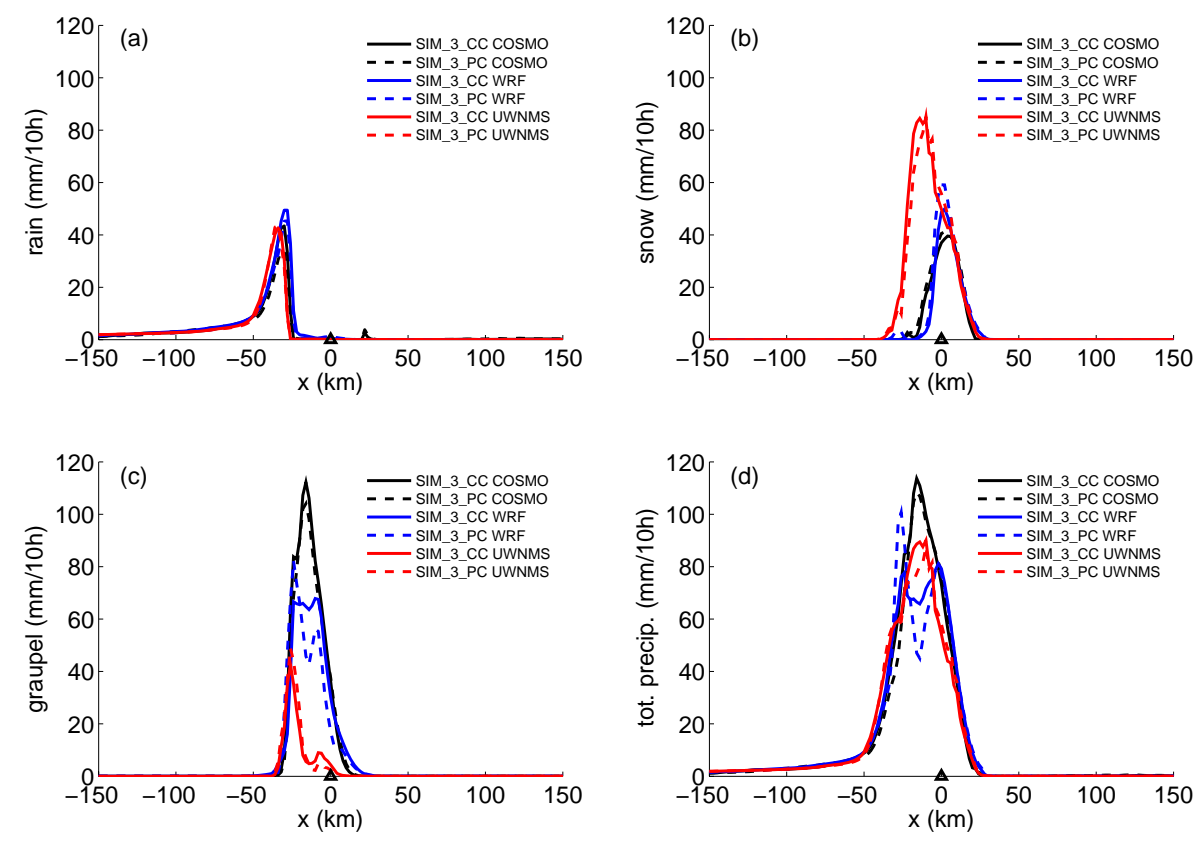

Fig. 17. Same as Fig. 9 but for simulation SIM_3_CC (solid) and SIM_3_PC (dashed).

important for cloud formation. All models develop a blocked air layer on the upstream side of the mountain with a depth of approximately $2800 \mathrm{~m}$. In this layer the horizontal wind speeds are decelerated to roughly $10 \mathrm{~m} \mathrm{~s}^{-1}$. The UWNMS model develops slightly stronger blocking than COSMO and WRF with a stagnant air layer at low levels and even slight reverse circulations. These differences may be attributable to differences in the numerics of the model or the VST coordinate system used in UWNMS.

\subsubsection{Clouds and precipitation comparison}

Similar to the previous case with unblocked flow, the cloud fields simulated by the models in the blocked flow case correspond qualitatively to the classical picture of a seeder-feeder cloud system with a liquid cloud at lower levels and an ice cloud aloft.

Figures 14 and 15 show the cloud fields in all three simulations of case SIM_3_CC averaged over the $10 \mathrm{~h}$ simulation 

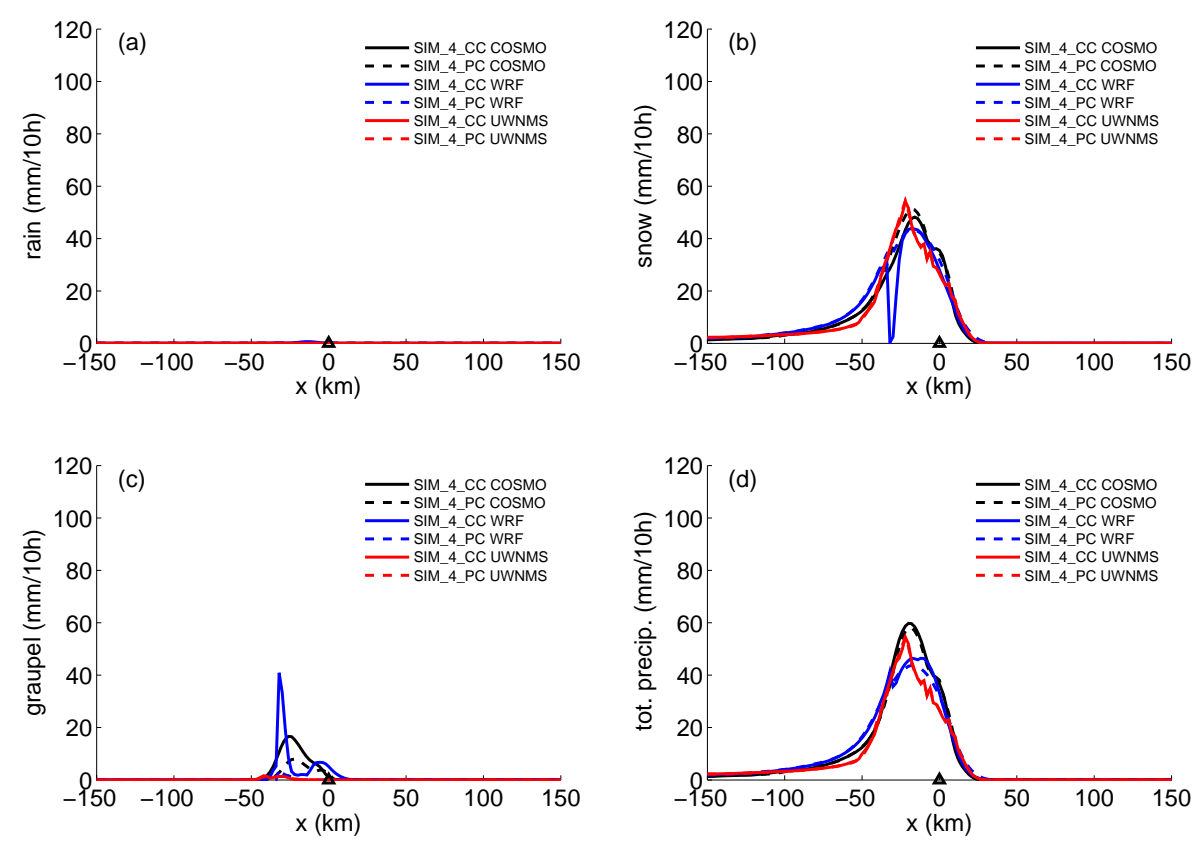

Fig. 18. Same as Fig. 9 but for simulation SIM_4_CC (solid) and SIM_4_PC (dashed).
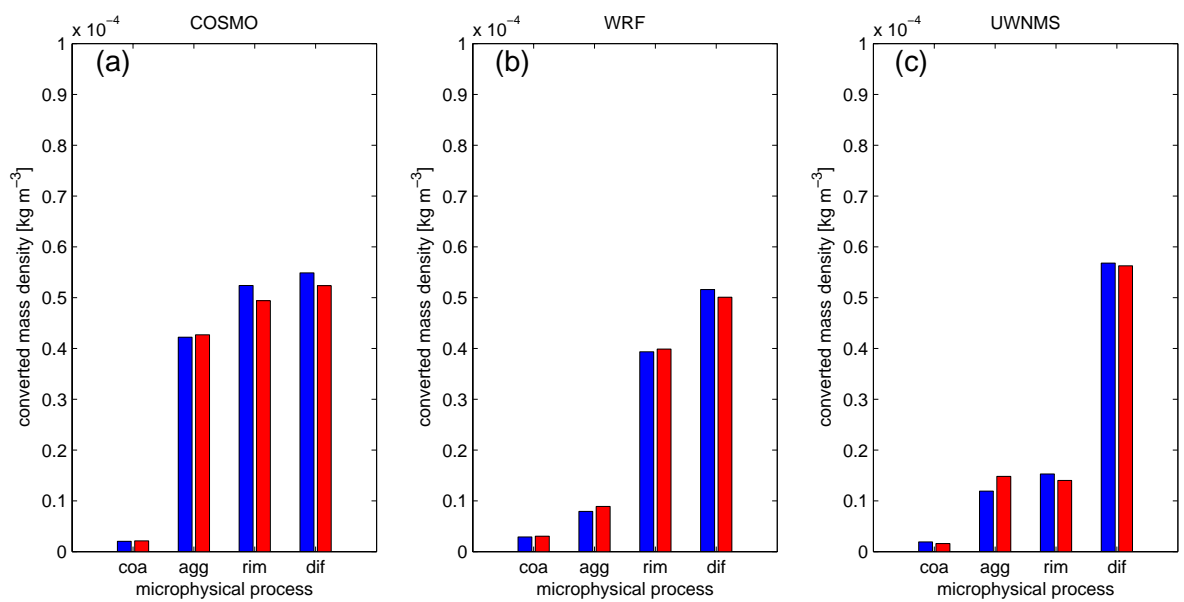

Fig. 19. Same as Fig. 10 but for the simulations SIM_3_CC (blue) and SIM_3_PC (red).

time. The simulated cloud is roughly $6.5 \mathrm{~km}$ deep in all models but there are discrepancies in the partitioning of the cloud water between the liquid and the ice phase. In COSMO most of the cloud consists of supercooled liquid water down to temperatures of $-20^{\circ} \mathrm{C}$ whereas, for example, in UWNMS the liquid-phase is confined to levels below approximately $1 \mathrm{~km}$ and above the pre-existing ice crystals grow by vapour deposition on the expense of the liquidphase (i.e., the Bergeron-Findeisen process). COSMO is the only model that simulates co-existing liquid and ice and sustains mixed-phase cloud patches. In both other models supercooled liquid water exists but is locally separated from the ice, which suggests that the Bergeron-Findeisen process is more effective in these models. Ice crystals are predominantly found between $2 \mathrm{~km}$ and $7 \mathrm{~km}$ but are rapidly aggregated to snow flakes in all models. The snow flakes then sediment into the lower layers where they start riming to graupel which enhances the orographic precipitation greatly. Most of the precipitation originates from snow and graupel with some contributions from rain that forms below the freezing level. In the simulations with increased aerosol number concentrations (SIM_3b) all models show an increase in the cloud droplet number concentrations but the ice crystal number concentrations are relatively unchanged (Fig. 16).

In the simulations SIM_4 the cloud fields are qualitatively similar to case SIM_3 (not shown) except that the ice part of 

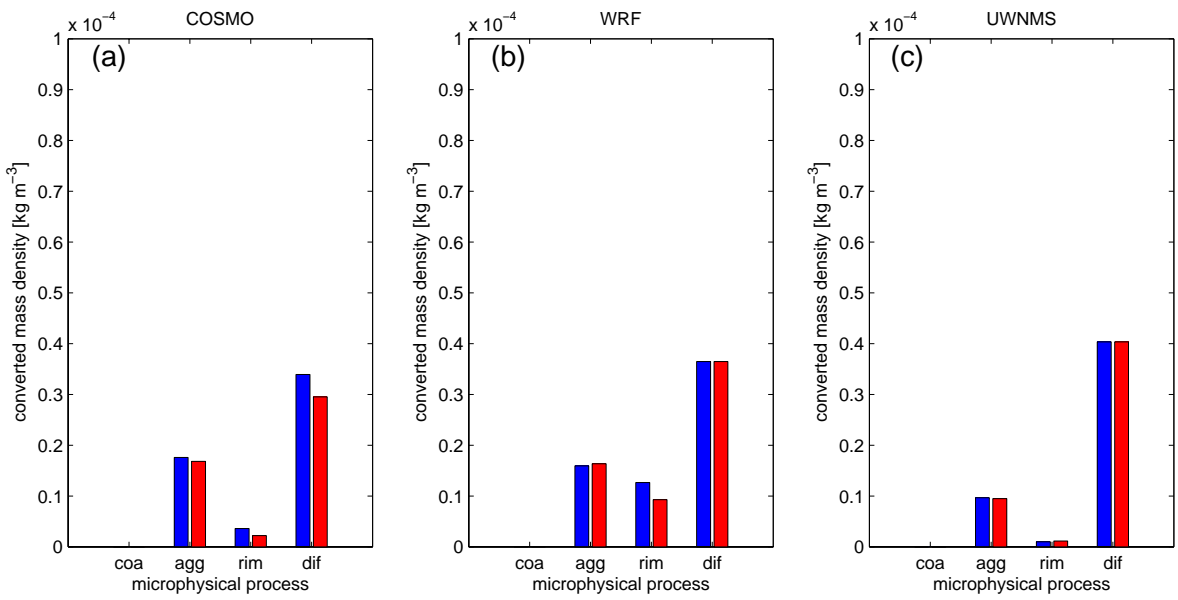

Fig. 20. Same as Fig. 10 but for the simulations SIM_4_CC (blue) and SIM_4_PC (red).

the cloud starts at much lower elevations and the contributions from the liquid phase are small.

The orographic precipitation distributions are shown in Fig. 17 for the case with warmer temperatures (SIM_3) and in Fig. 18 for the case with colder temperatures (SIM_4), respectively. Despite the fact the dynamical differences in the individual model simulations are generally larger in the case with flow blocking than in the unblocked flow case the amount of total precipitation is in better agreement with some but overall less variability among the models. All models agree on the qualitative shape of the orographic precipitation distribution (Fig. 17). There is good correspondence of the spatial distribution of rain whereas for snow and graupel the location of the peaks vary due to the different fall velocities for snow and graupel used in the models. Furthermore, there are discrepancies regarding the contributions from snow and graupel to the total precipitation whereas there is little variation in terms of rain. COSMO is the model with most precipitation whereas UWNMS is the model with least precipitation. Similar results are found in the simulations SIM_4 with the distinction that contributions from rain are negligible in all models (Fig. 18). There is a good agreement in terms of total precipitation and the result that most of the precipitation is due to snow. Again, there is some discrepancy in the precipitation from graupel particles.

The sensitivity of orographic precipitation with respect to changes in aerosol number concentration is much smaller and almost negligible for the blocked flow case in both the warm and the cold subset of the simulations. All models show a tendency towards reduced total orographic precipitation but the sensitivities do not exceed $3 \%$ in any of the simulations (see Table 4 for details). Some of the simulations show an increase of SP in the polluted case which points to a slight redistribution of precipitation towards the leeward side of the mountain. The DR shows only a weak signal in most of the simulations (see Tables 5 and 6 for details.)

\subsubsection{Microphysics comparison}

Figures 19 and 20 show the microphysical rates for the simulations SIM_3 and SIM_4, respectively. Similar to the case with small mountain and warmer temperature (SIM_1) all models concur that diffusional growth is the dominant microphysical process. Two (COSMO and WRF) out of three models suggest that riming is the prevalent microphysical process involving hydrometeor collections whereas in the UWNMS model aggregation and riming are equally important. In all models, the coalescence process contributes only little to the overall precipitation. In the simulations with increased aerosol number concentrations the net diffusional growth is decreased consistently in all models. Riming is found to decrease with increasing aerosol number concentrations in COSMO and UWNMS but is increased in WRF. Furthermore, all models show an increase in aggregation with increasing aerosol concentrations. The coalescence process is only little affected because the decrease in the coalescence of cloud droplets is largely compensated by the accretion of cloud droplets by rain that is produced from melting ice hydrometeors. Similar results are found in the set of simulations with colder temperature SIM_4. However, in this case all models suggest that aggregation is the dominant collection process followed by riming and agree on the negligibly small contribution from coalescence.

\section{Discussion and conclusions}

A model intercomparison of aerosol-cloud-precipitation interactions in stratiform orographic mixed-phase clouds is conducted and the sensitivities of orographic precipitation to changes in aerosol number concentrations are analysed and compared among the models. Furthermore, the sensitivities of microphysical processes such as coalescence, aggregation, riming and diffusional growth are evaluated. 
Idealized simulations of flow past topography are performed for two different flow regimes: a linear mountain wave flow regime without significant orographic flow blocking and a flow regime with strong orographic flow blocking. Additional sensitivity studies are carried out by changing the vertical temperature profiles, which leads to clouds with varying ice phase contributions. The simulations are initialized with aerosol size distributions typical and representative for remote-continental conditions in the Alpine region.

The simulated cloud types resemble orographic seederfeeder clouds with sustained mixed-phase conditions sandwiched between layers of partly supercooled liquid below and layers of ice above. These types of clouds are a well known prototype of orographic clouds at mid-latitudes and are climatologically important for explaining observed orographic precipitation amounts especially over small mountain ranges (e.g., Browning et al., 1974; Smith, 1989).

The results of the model intercomparison suggest that the sensitivity of orographic precipitation to changes in the aerosol number concentrations varies from case to case but also from model to model. While a case dependent sensitivity of aerosol-cloud-precipitation is generally found in many other studies (e.g., Levin and Cotton, 2009; Khain, 2009) the variability among different models and microphysical approaches for the same case is less recognized. In most of the simulations a decrease of orographic precipitation with increasing aerosol number concentrations is found whereas in some others orographic precipitation is either only marginally affected or slightly increased. Thus, neither a precipitation decrease nor a precipitation increase is found robustly in all simulations. Qualitative robust results can only be found for a small subset of the simulations. However, even for this small subset of simulations quantitative estimates of the sensitivity of orographic precipitation to aerosol perturbations vary greatly among the models.

Estimates for the aerosol effect on orographic precipitation range from $-19 \%$ to $0 \%$ depending on the simulated case and the model. Nevertheless, a tendency towards smaller precipitation sensitivities is found for the cases with high mountain range or low temperatures. Orographic clouds and precipitation are found most susceptible to changes in aerosol number concentrations in the case of a small mountain range and warm temperatures. These sensitivities can be understood qualitatively from two different points of view. From a microphysical point of view it may be argued that both factors, increasing the height of the mountain range or decreasing the ambient temperature, strengthen the role of the ice phase in the simulations thereby reducing the susceptibility of the clouds to aerosol perturbations. On the other hand, similar sensitivities are also found in simulations of warm-phase orographic clouds with no contribution from the ice phase (Muhlbauer and Lohmann, 2008). Thus, from a dynamical point of view, orographic clouds are found less susceptible to aerosol modifications in the blocked flow case because air parcels in these clouds do not obey the classi- cal picture of a flow over the mountain that constrains the available time for the initiation of precipitation. Hence, one may expect an aerosol effect on precipitation to be less pronounced or even inverted in regions with high terrain (e.g., the Alps or Rocky Mountains) or in regions where ice-phase microphysics play an important role for the climatology of orographic precipitation.

There is an agreement among the models that on average the LWP is increased with increasing aerosol number concentrations. In some cases an increase in the IWP is also found but this feature is less robust and not supported by all models. Most of the simulations are not particularly sensitive to the aerosol modification because the cloud droplet coalescence process is overall only slightly affected in the simulated orographic clouds. The reasons are twofold: firstly, in the simulated cases with cold temperatures the contributions from the coalescence process to the orographic precipitation are found to be negligibly small and, thus, changes in this particular microphysical process are not important for the precipitation formation. Secondly, in the simulated cases with warm temperatures rain drops are mainly produced by melting of ice hydrometeors generated aloft and not by the coalescence of the cloud droplets. Thus, the efficient production of rain drops in mixed-phase clouds does not hinge on the cloud droplet coalescence process alone. These rain drops then fall through layers of enhanced liquid water content and collect cloud droplets more efficiently, thereby partly compensating for the reduced cloud droplet coalescence.

Microphysical processes that either reduce the effect of aerosols on precipitation or lead to increasing precipitation with increasing aerosol number concentrations have also been reported in cases where rain drops are generated efficiently by giant CCN (e.g., Feingold et al., 1999; Rosenfeld et al., 2002) or due to vertically decreasing aerosol number concentrations that support early rain drop formation through coalescence in the upper regions of a cloud (Muhlbauer and Lohmann, 2008). These mechanisms can be operational and effective even without aid from the ice phase.

The simulations conducted in this study also suggest that a decrease in the coalescence process does not necessarily imply a decrease in precipitation. The reason is that riming can be increased if more cloud liquid water is available for collection in the case of high aerosol number concentrations. It is emphasized that riming is found to decrease as well as increase in the simulations depending on the case and the model. Hence, there is no robust conclusion whether riming is increased or decreased with increasing aerosol number concentrations in the simulated orographic clouds. Furthermore, a simulated decrease in riming does not imply a decrease in precipitation because the decrease in riming can be compensated by an increase in aggregation.

The disagreement among the models regarding the sensitivity of microphysical processes and the eventual macrophysical outcome in terms of precipitation is linked to the 
uncertainties in representing microphysical processes especially in mixed-phase and ice clouds. Some of the persistent discrepancies found in all simulations of the model intercomparison are related to the partitioning of cloud water between the liquid and the ice phase, the simulation of mixed-phase conditions and the partitioning of precipitation between snow and graupel. Some of these problems reflect the incomplete and limited physical understanding of cloud microphysics (e.g., initiation of ice in mixed-phase clouds by heterogeneous ice nucleation), the fact that many microphysical processes are not very well constrained by observations (e.g., uncertainty of the ice aggregation efficiencies) and the artificial treatment of microphysical processes in numerical models (e.g., the treatment of rimed snow and the conversion to graupel). The latter problem might be mitigated by avoiding artificial hydrometeor categorization in cloud-microphysics schemes as suggested by Hashino and Tripoli (2007) or Morrison and Grabowski (2008). However, more observations from laboratory studies and field campaigns are needed to improve the current understanding of aerosol-cloud-precipitation interactions and to better constrain cloud-microphysical parametrisations.

Acknowledgements. We appreciate the help of two anonymous reviewers who provided very thourough and constructive reviews of the manuscript. We thank the World Meteorological Organization (WMO) for sponsoring the 7th WMO Cloud Modeling Workshop held in Cozumel, Mexico, at 14-17 July 2008 and all the participants for fruitful discussions, suggestions and comments. The first author is grateful to Axel Seifert for sharing his cloud-microphysics code. We acknowledge the following institutions for providing computing time: the European Center for Medium-Range Weather Forecasts (ECMWF) within the special project Cloud Aerosol Interactions, the German Weather Service (DWD), the National Science Foundation (NSF) and the National Center for Atmospheric Research (NCAR).

Edited by: G. Roberts

\section{References}

Alpert, P., Halfon, N., and Levin, Z.: Does air pollution really suppress precipitation in Israel?, J. Appl. Meteor. Climatol., 47, 933-943, 2008.

Baker, M. B. and Peter, T.: Small-scale cloud processes and climate, Nature, 451, 299-300, doi:10.1038/nature06594, 2008.

Bohm, H.: A general hydrodynamic theory for mixed-phase microphysics. Part I: Drag and fall speed of hydrometeors, Atmos. Res., 27, 253-274, 1992.

Borys, R., Lowenthal, D., and Mitchell, D.: The relationships among cloud microphysics, chemistry, and precipitation rate in cold mountain clouds, Atmos. Environ., 34, 2593-2602, 2000.

Borys, R., Lowenthal, D., Cohn, S., and Brown, W.: Mountaintop and radar measurements of anthropogenic aerosol effects on snow growth and snowfall rate, Geophys. Res. Lett., 30, 15381542, 2003.
Bott, A.: A Positive Definite Advection Scheme Obtained by Nonlinear Renormalization of the Advective Fluxes, Mon. Weather Rev., 117, 1006-1015, 1989.

Bougeault, P., Binder, P., Buzzi, A., Dirks, R., Houze, R., Kuettner, J., Smith, R. B., Steinacker, R., and Volkert, H.: The MAP Special Observing Period, B. Am. Meteor. Soc., 82, 433-462, 2001.

Browning, K. A., Hill, F. F., and Pardoe, C. W.: Structure and mechanism of precipitation and effect of orography in a wintertime warm sector, Q. J. Roy. Meteorol. Soc., 100, 309-330, 1974.

Chaumerliac, N., Richard, E., and Pinty, J.: Sulfur Scavenging in a Mesoscale Model With Quasi-Spectral Microphysics: TwoDimensional Results for Continental and Maritime Clouds, J. Geophys. Res., 92, 3114-3126, 1987.

Choularton, T., Bower, K., Weingartner, E., Crawford, I., Coe, H., Gallagher, M., Flynn, M., Crosier, J., Connolly, P., Targino, A., Alfarra, M., Baltensperger, U., Sjogren, S., Verheggen, B., Cozic, J., and Gysel, M.: The influence of small aerosol particles on the properties of water and ice clouds, Faraday Discuss., 137, 205-222, 2008.

Clark, T. L. and Farley, R.: Severe Downslope Windstorm Calculations in Two and Three Spatial Dimensions Using Anelastic Interactive Grid Nesting: A Possible Mechanism for Gustiness, J. Atmos. Sci., 41, 329-350, 1984.

Cozic, J., Verheggen, B., Weingartner, E., Crosier, J., Bower, K. N., Flynn, M., Coe, H., Henning, S., Steinbacher, M., Henne, S., Collaud Coen, M., Petzold, A., and Baltensperger, U.: Chemical composition of free tropospheric aerosol for $\mathrm{PM}_{1}$ and coarse mode at the high alpine site Jungfraujoch, Atmos. Chem. Phys., 8, 407-423, doi:10.5194/acp-8-407-2008, 2008.

Cziczo, D. J., Murphy, D., Hudson, P., and Thomson, D.: Singleparticle measurements of the chemical composition of cirrus ice residue during CRYSTAL-FACE, J. Geophys. Res., 109, D04201, doi:10.1029/2003JD004032, 2004.

DeMott, P. J., Sassen, K., Poellot, M. R., Baumgardner, D., Rogers, D. C., Brooks, S. D., Prenni, A. J., and Kreidenweis, S. M.: African dust aerosols as atmospheric ice nuclei, Geophys. Res. Lett., 30, 1732, doi:10.1029/2003GL017410, 2004.

Denman, K.L., Brasseur, G., Chidthaisong, A., Ciais, P., Cox, P., Dickinson, R., Hauglustaine, D., Heinze, C., Holland, E., Jacob, D., Lohmann, U., Ramachandran, S., da Silva Dias, P., Wofsy, S., and Zhang, X.: Climate Change 2007: The Physical Science Basis. Contribution of Working Group I to the Fourth Assessment Report of the Intergovernmental Panel on Climate Change, chap. Couplings Between Changes in the Climate System and Biogeochemistry, 499-588, Cambridge University Press, Cambridge, United Kingdom and New York, NY, USA, 2007.

Doms, G. and Schättler, U.: A Description of the Nonhydrostatic Regional Model LM. Part I: Dynamics and Numerics, Tech. rep., Deutscher Wetterdienst, Offenbach, Germany, 2002.

Durran, D. and Klemp, J.: A Compressible Model for the Simulation of Moist Mountain Waves, Mon. Weather Rev., 111, 23412361, 1983.

Feingold, G., Cotton, W. R., Kreidenweis, S. M., and Davis, J. T.: The impact of giant cloud condensation nuclei on drizzle formation in stratocumulus: Implications for cloud radiative properties, J. Atmos. Sci., 56, 4100-4117, 1999.

Field, P. R., Cotton, R. J., Noone, K., Glantz, P., Kaye, P. H., Hirst, E., Greenaway, R. S., Jost, C., Gabriel, R., Reiner, T., Andreae, M., Saunders, C. P. R., Archer, A., Choularton, T., Smith, M., 
Brooks, B., Hoell, C., Bandy, B., Johnson, D., and Heymsfield, A.: Ice nucleation in orographic wave clouds: Measurements made during INTACC, Q. J. Roy. Meteorol. Soc., 127, 14931512, 2001.

Geresdi, I.: Idealized simulation of the Colorado hailstorm case: Comparison of bulk and detailed microphysics, Atmos. Res., 45, 237-252, 1998.

Geresdi, I. and Rasmussen, R.: Freezing drizzle formation in stably stratified layer clouds. Part II: The role of giant nuclei and aerosol particle size distribution and solubility, J. Atmos. Sci., 62, 20372057, 2005.

Givati, A. and Rosenfeld, D.: Quantifying Precipitation Suppression Due to Air Pollution, J. Appl. Meteor., 43, 1038-1056, 2004.

Gorbunov, B., Baklanov, A., Kakutkina, N., Windsor, H., and Toumi, R.: Ice nucleation on soot particles, J. Aerosol Sci., 32, 200-215, 2001

Hall, W. D.: A detailed micrphysical model within a twodimensional framework: Model description and preliminary results, J. Atmos. Sci., 37, 2486-2507, 1980.

Hallgren, R. E. and Hosler, C. L.: Preliminary results on the aggregation of ice crsytals, Geophys. Monogr., 5, 257-263, 1960.

Hashino, T. and Tripoli, G. J.: The Spectral Ice Habit Prediction System (SHIPS). Part I: Model Description and Simulation of the Vapor Deposition, J. Atmos. Sci., 64, 2210-2237, 2007.

Hashino, T. and Tripoli, G. J.: The Spectral Ice Habit Prediction System (SHIPS). Part II: Simulation of nucleation and depositional growth of polycrystals, J. Atmos. Sci., 65, 3071-3094, 2008.

Hashino, T. and Tripoli, G. J.: The Spectral Ice Habit Prediction System (SHIPS). Part III: Description of the ice particle model and the habit-dependent aggregation process, to be submitted to J. Atmos. Sci., 2010a.

Hashino, T. and Tripoli, G. J.: The Spectral Ice Habit Prediction System (SHIPS). Part IV: Box model simulations of the habitdependent aggregation process, to be submitted to J. Atmos. Sci., $2010 \mathrm{~b}$.

Hegg, D. A. and Baker, M. B.: Nucleation in the atmosphere, Rep. Prog. Phys., 72, 056801, doi:10.1088/0034-4885/72/5/056801, 2009.

Heymsfield, A. J. and Kajikawa, M.: An improved approach to calculating terminal fall velocities of plate-like crystals and graupel, J. Atmos. Sci., 44, 1088-1099, 1987.

Hobbs, P., Easter, R., and Fraser, A.: A theoretical study of the flow of air and fallout of solid precipitation over mountainous terrain: Part II. Microphysics, J. Atmos. Sci., 30, 813-823, 1973.

Hobbs, P. V.: Ice Physics, Oxford Press, 837 pp., 1974.

Jiang, Q. and Smith, R.: Cloud Timescales and Orographic Precipitation, J. Atmos. Sci., 60, 1543-1559, 2003.

Jirak, I. L. and Cotton, W. R.: Effect of Air Pollution on Precipitation along the Front Range of the Rocky Mountains, J. Appl. Meteor., 45, 236-245, 2006.

Kanji, Z. A. and Abbatt, J. P. D.: Laboratory studies of ice formation via deposition mode nucleation onto mineral dust and n-hexane soot samples, J. Geophys. Res., 111, D16204, doi:10.1029/2005JD006766, 2006.

Khain, A., Ovtchinnikov, M., Pinsky, M., Pokrovsky, A., and Krugliak, H.: Notes on the state-of-the-art numerical modeling of cloud microphysics, Atmos. Res., 55, 159-224, 2000.
Khain, A. P.: Notes on state-of-the-art investigations of aerosol effects on precipitation: a critical review, Env. Res. Lett., 4, 015004, doi:10.1088/1748-9326/4/1/015004, 2009.

Khain, A. P., BenMoshe, N., and Pokrovsky, A.: Factors determining the impact of aerosols on surface precipitation from clouds: An attempt at classification, J. Atmos. Sci., 65, 1721-1748, 2008.

Klemp, J. B., Dudhia, J., and Hassiotis, A. D.: An Upper GravityWave Absorbing Layer for NWP Applications, Mon. Weather Rev., 136, 3987-4004, 2008.

Klemp, J. B., Skamarock, W. C., and Dudhia, J.: Conservative splitexplicit time integration methods for the compressible nonhydrostatic equations, Mon. Weather Rev., 135, 2897-2913, 2007.

Kogan, Y.: The simulation of a convective cloud in a 3-D model with explicit microphysics: Part I. Model description and sensitivity experiments, J. Atmos. Sci., 48, 1160-1189, 1991.

Kulkarni, G. and Dobbie, S.: Ice nucleation properties of mineral dust particles: determination of onset RHi, IN active fraction, nucleation time-lag, and the effect of active sites on contact angles, Atmos. Chem. Phys., 10, 95-105, doi:10.5194/acp-10-95-2010, 2010.

Levin, Z. and Cotton, W. R.: Aerosol Pollution Impact on Precipitation: A Scientific review, Springer, 2009.

Lew, J. K., Montague, D. C., and Pruppacher, H. R.: A wind tunnel investigation on the riming of snowflakes. Part I: Porous disks and large stellars, J. Atmos. Sci., 43, 2392-2409, 1986.

Li, X., Tao, W.-K., Khain, A. P., Simpson, J., and Johnson, D. E.: Sensitivity of a Cloud-Resolving Model to Bulk and Explicit Bin Microphysical Schemes. Part I: Comparisons, J. Atmos. Sci., 66, 3-21, 2009.

Lin, Y. L., Farley, R. D., and Orville, H.: Bulk parameterization of the snow field in a cloud model, J. Clim. Appl. Meteorol., 22, 1065-1092, 1983.

Locatelli, J. D. and Hobbs, P. V.: Fall speeds and masses of solid precipitation particles, J. Geophys. Res., 79, 2185-2197, 1974.

Lowenthal, D. H., Borys, R. D., Choularton, T. W., Bower, K. N., Flynn, M. J., and Gallagher, M. W.: Parameterization of the cloud droplet-sulfate relationship, Atmos. Environ., 38, 287 292, 2004.

Lynn, B., Khain, A., Rosenfeld, D., and Woodley, W. L.: Effects of aerosols on precipitation from orographic clouds, J. Geophys. Res., 112, D10225, doi:10.1029/2006JD007537, 2007.

Mertes, S., Verheggen, B., Walter, S., Connolly, P., Ebert, M., Schneider, J., Bower, K. N., Cozic, J., Weinbruch, S., Baltensperger, U., and Weingartner, E.: Counterflow virtual impact or based collection of small ice particles in mixed-phase clouds for the physico-chemical characterization of tropospheric ice nuclei : Sampler description and first case study, Aerosol Sci. Tech., 41, 848-864, 2007.

Meyers, M., DeMott, P., and Cotton, W.: New primary icenucleation parameterizations in an explicit cloud model, J. Appl Meteor., 31, 708-721, 1992.

Mitchell, D. L.: Evolution of snow-size spectra predicted by the growth processes of diffusion, aggregation and riming, Conference on Cloud Physics, Am. Meteorol. Soc., San Francisco, Calif., 1990.

Mohler, O., Buttner, S., Linke, C., Schnaiter, M., Saathoff, H., Stetzer, O., Wagner, R., Kramer, M., Mangold, A., Ebert, V., and Schurath, U.: Effect of sulfuric acid coating on heterogeneous ice nucleation by soot aerosol particles, J. Geophys. Res., 110, 
D11210, doi:10.1029/2004JD005169, 2005.

Mohler, O., Benz, S., Saathoff, H., Schnaiter, M., Wagner, R., Schneider, J., Walter, S., Ebert, V., and Wagner, S.: The effect of organic coating on the heterogeneous ice nucleation efficiency of mineral dust aerosols, Environ. Res. Lett., 3, 025007, doi:10.1088/1748-9326/3/2/025007, 2008.

Morrison, H. and Grabowski, W. W.: Comparison of bulk and bin warm-rain microphysics models using a kinematic framework, J. Atmos. Sci., 64, 2839-2861, 2007.

Morrison, H. and Grabowski, W. W.: A novel approach for representing ice microphysics in models: Description and tests using a kinematic framework, J. Atmos. Sci., 65, 1528-1548, 2008.

Morrison, H., Thompson, G., Gilmore, M., Gong, W., Leaitch, R., and Muhlbauer, A.: WMO International Cloud Modeling Workshop, Bull. Amer. Meteor. Soc., 90, 1683-1686, 2009.

Mühlbauer, A.: Aerosol-Cloud-Precipitation Interactions in Moist Orographic Flows: Sensitivity Studies with a Numerical Model, chap. Statistical analysis of the indirect aerosol effect on orographic precipitation, 164 pp., Suedwestdeutscher Verlag fuer Hochschulschriften, 2009.

Muhlbauer, A. and Lohmann, U.: Sensitivity studies of the role of aerosols in warm-phase orographic precipitation in different dynamical flow regimes, J. Atmos. Sci., 65, 2522-2542, 2008.

Muhlbauer, A. and Lohmann, U.: Sensitivity studies of aerosolcloud interactions in mixed-phase orographic precipitation, J. Atmos. Sci., 66, 2517-2538, 2009.

Paldor, N.: On the Estimation of Trends in Annual Rainfall Using Paired Gauge Observations, J. Appl. Meteor. Climatol., 47, 1814-1818, 2008.

Passarelli, R. E. and Srivastava, R. C.: New aspect of the vertical incidence doppler spectrum of falling snowflakes, B. Am. Meteor. Soc., 60, 1513-1513, 1979.

Petters, M. D. and Kreidenweis, S. M.: A single parameter representation of hygroscopic growth and cloud condensation nucleus activity, Atmos. Chem. Phys., 7, 1961-1971, doi:10.5194/acp-71961-2007, 2007.

Pinsky, M., Khain, A., and Shapiro, M.: Collision efficiency of drops in a wide range of Reynolds numbers: Effect of pressure on spectrum evolution, J. Atmos. Sci., 58, 742-764, 2001.

Pitter, R. L.: Re-examination of riming on thin ice plates, J. Atmos. Sci., 34, 684-685, 1977.

Pruppacher, H. and Klett, J.: Microphysics of Clouds and Precipitation, Kluwer Academic Publishers, 2nd edn., 1997.

Rasmussen, R., Geresdi, I., Thompson, G., Manning, K., and Karplus, E.: Freezing drizzle formation in stably stratified layer clouds: The role of radiative cooling of cloud droplets, cloud condensation nuclei, and ice initiation, J. Atmos. Sci., 59, 837$860,2002$.

Rasmussen, R. M. and Heymsfield, A. J.: Melting and shedding of graupel and hail. 1. Model physics, J. Atmos. Sci., 44, 27542763, 1987.

Reisin, T., Levin, Z., and Tzivion, S.: Rain production in convective clouds as simulated in an axisymmetric model with detailed microphysics .1. Description of the model, J. Atmos. Sci., 53, 497-519, 1996.

Roberts, P. and Hallett, J.: A laboratory study of the ice nucleating properties of some mineral particulates, Q. J. Roy. Meteorol. Soc., 94, 25-34, 1968.

Roe, G. H.: Orographic Precipitation, Annu. Rev. Earth Planet. Sci.,
33, 645-671, 2005.

Rosenfeld, D., Lahav, R., Khain, A., and Pinsky, M.: The role of sea spray in cleansing air pollution over ocean via cloud processes, Science, 297, 1667-1670, 2002.

Rotunno, R. and Houze, R. A.: Lessons on orographic precipitation from the Mesoscale Alpine Programme, Q. J. Roy. Meteorol. Soc., 133, 811-830, 2007.

Saleeby, S. M. and Cotton, W. R.: Influence of Cloud Condensation Nuclei on Orographic Snowfall, J. Appl. Meteor. Climatol., 48, 903-922, 2009.

Schär, C., Leuenberger, D., Fuhrer, O., Lüthi, D., and Girard, C.: A New Terrain-Following Vertical Coordinate Formulation for Atmospheric Prediction Models, Mon. Weather Rev., 130, 24592480, 2002.

Seifert, A. and Beheng, K. D.: A two-moment cloud microphysics parameterization for mixed-phase clouds. Part I: Model Description, Meteorol. Atmos. Phys., 92, 45-66, 2006.

Skamarock, W. C. and Klemp, J. B.: A time-split nonhydrostatic atmospheric model for weather research and forecasting applications, J. Comput. Phys., 227, 3465-3485, 2008.

Smith, R. B.: Mechanisms of orographic precipitation, Meteorol. Mag., 118, 85-88, 1989.

Smith, R. B., Jiang, Q., Fearon, M. G., Tabary, P., Dorninger, M., Doyle, J. D., and Benoit, R.: Orographic precipitation and air mass transformation: An Alpine example, Q. J. Roy. Meteorol. Soc., 129, 433-454, 2003.

Smith, R. B., Barstad, I., and Bonneau, L.: Orographic Precipitation and Oregon's Climate Transition, J. Atmos. Sci., 62, 177-191, 2005.

Steppeler, J., Doms, G., Schättler, U., Bitzer, H., Gassmann, A., Damrath, U., and Gregoric, G.: Meso-gamma scale forecasts using the nonhydrostatic model LM, Meteorol. Atmos. Phys., 82, 75-96, 2003.

Stoelinga, M., Hobbs, P., Mass, C., Locatelli, J., Collie, B., Houze, R., Rangno, A., Bond, N., Smull, B., Rasmussen, R., Thompson, G., and Colman, B.: Improvement of microphysical parameterization through observational verification experiment, B. Am. Meteor. Soc., 84, 1807-1826, 2003.

Targino, A. C., Krejci, R., Noone, K. J., and Glantz, P.: Single particle analysis of ice crystal residuals observed in orographic wave clouds over Scandinavia during INTACC experiment, Atmos. Chem. Phys., 6, 1977-1990, doi:10.5194/acp-6-1977-2006, 2006.

Teller, A. and Levin, Z.: The effects of aerosols on precipitation and dimensions of subtropical clouds: a sensitivity study using a numerical cloud model, Atmos. Chem. Phys., 6, 67-80, doi:10.5194/acp-6-67-2006, 2006.

Thompson, G., Rasmussen, R., and Manning, K.: Explicit Forecasts of Winter Precipitation Using an Improved Bulk Microphysics Scheme. Part I: Description and Sensitivity Analysis, Mon. Weather Rev., 132, 519-542, 2004.

Tripoli, G. J.: A nonhydrostatic mesoscale model designed to simulate scale interaction, Mon. Weather Rev., 120, 1342-1359, 1992.

Tripoli, G. J. and Smith, E. A.: Scalable nonhydrostatic regionalmesoscale-cloud model featuring variable-stepped topography coordinates: formulation and performance on classic obstacle flow problems, to be submitted to Mon. Weather Rev., 2010.

Twomey, S., Piepgrass, M., and Wolfe, T.: An assessment of the impact of pollution on global cloud albedo, Tellus B, 36, 356- 
366, 1984.

Tzivion, S., Feingold, G., and Levin, Z.: An efficient numerical solution to the stochastic collection equation, J. Atmos. Sci., 44, 3139-3149, 1987.

Vali, G.: Nucleation terminology, J. Aerosol Sci., 16, 575-576, 1985.

Verheggen, B., Cozic, J., Weingartner, E., Bower, K., Mertes, S., Connolly, P., Gallagher, M., Flynn, M., Choularton, T., and Baltensperger, U.: Aerosol partitioning between the interstitial and the condensed phase in mixed-phase clouds, J. Geophys. Res., 112, D23202, doi:10.1029/2007JD008714, 2007.

Wang, H., Skamarock, W. C., and Feingold, G.: Evaluation of Scalar Advection Schemes in the Advanced Research WRF Model using Large-Eddy Simulations of Aerosol-Cloud Interactions, Mon. Weather Rev., 137, 2547-2558, 2009.
Weingartner, E., Nyeki, S., and Baltensperger, U.: Seasonal and diurnal variation of aerosol size distributions $(10<D<750 \mathrm{~nm})$ at a high-alpine site (Jungfraujoch $3580 \mathrm{~m}$ asl), J. Geophys. Res., 104, 26809-26820, 1999.

Wicker, L. J. and Skamarock, W. C.: Time-splitting methods for elastic models using forward time schemes, Mon. Weather Rev., 130, 2088-2097, 2002.

Xue, L., Teller, A., Rasmussen, R., Geresdi, I., and Pan, Z.: Effects of aerosol solubility and regeneration on warm-phase orographic clouds and precipitation simulated by a detailed bin microphysical scheme, J. Atmos. Sci., in press, 2010. 